\title{
Proteomic portraits reveal evolutionarily conserved and divergent responses to spinal cord injury
}

\author{
Michael A. Skinnider ${ }^{1}$, Jason Rogalski ${ }^{1}$, Seth Tigchelaar $^{2}$, Neda Manouchehri ${ }^{2}$, Anna Prudova ${ }^{1}$, \\ Angela M. Jackson ${ }^{3}$, Karina Nielsen ${ }^{1}$, Jaihyun Jeong ${ }^{1}$, Shalini Chaudhary ${ }^{1}$, Katelyn Shortt ${ }^{2}$, \\ Ylonna Gallagher-Kurtzke ${ }^{1,2}$, Kitty So ${ }^{2}$, Allan Fong ${ }^{2}$, Rishab Gupta ${ }^{2}$, Elena B. Okon ${ }^{2}$, Michael A. Rizzuto ${ }^{2}$ Kevin Dong $^{2}$, \\ Femke Streijger $^{2}$, Lise Belanger ${ }^{4}$, Leanna Ritchie ${ }^{4}$, Angela Tsang ${ }^{4}$, Sean Christie ${ }^{5}$, Jean-Marc Mac-Thiong ${ }^{6,7}$, \\ Christopher Bailey $^{8}$, Tamir Ailon $^{9}$, Raphaele Charest-Morin ${ }^{10}$, Nicholas Dea ${ }^{9}$, Jefferson R. Wilson ${ }^{11}$, Sanjay Dhall ${ }^{12}$, \\ Scott Paquette ${ }^{9}$, John Street ${ }^{10}$, Charles G. Fisher ${ }^{10}$, Marcel F. Dvorak ${ }^{2,10}$, Casey Shannon ${ }^{13}$, Christoph Borchers ${ }^{3}$, \\ Robert Balshaw $^{13}$, Leonard J. Foster ${ }^{1,14^{*}}$, and Brian K. Kwon ${ }^{2,10^{*}}$ \\ ${ }^{1}$ Michael Smith Laboratories, University of British Columbia, Vancouver, BC, Canada \\ ${ }^{2}$ International Collaboration on Repair Discoveries (ICORD), University of British Columbia, Vancouver, BC, Canada \\ ${ }^{3}$ UVic-Genome BC Proteomics Centre, Victoria, BC, Canada \\ ${ }^{4}$ Vancouver Spine Program, Vancouver, BC, Canada \\ ${ }^{5}$ Division of Neurosurgery, Dalhousie University, Halifax, NS, Canada \\ ${ }^{6}$ Department of Surgery, Hôpital du Sacré-Coeur de Montréal, Montréal, QC, Canada \\ ${ }^{7}$ Chu Sainte-Justine, Department of Surgery, Université de Montréal, Montréal, QC, Canada \\ ${ }^{8}$ Division of Orthopaedic Surgery, London Health Sciences Centre, University of Western Ontario, London, ON, Canada \\ ${ }^{9}$ Division of Neurosurgery, University of British Columbia, Vancouver, BC, Canada \\ ${ }^{10}$ Department of Orthopaedics, Division of Spine, University of British Columbia, Vancouver, BC, Canada \\ ${ }^{11}$ Division of Neurosurgery, University of Toronto, St. Michael's Hospital, Toronto, ON, Canada \\ ${ }^{12}$ Department of Neurosurgery, University of California San Francisco, San Francisco, CA, USA \\ ${ }^{13}$ Prevention of Organ Failure (PROOF) Centre of Excellence, Vancouver, BC, Canada \\ ${ }^{14}$ Department of Biochemistry and Molecular Biology, University of British Columbia, Vancouver, BC, Canada \\ *email: foster@msl.ubc.ca, brian.kwon@ubc.ca
}

Despite the emergence of promising therapeutic approaches in preclinical studies, the failure of large-scale clinical trials leaves clinicians without effective treatments for acute spinal cord injury (SCI). These trials are hindered by their reliance on detailed neurological examinations to establish outcomes, which inflate the time and resources required for completion. Moreover, therapeutic development takes place in animal models whose relevance to human injury remains unclear. Here, we address these challenges through targeted proteomic analyses of CSF and serum samples from 111 acute SCI patients and, in parallel, a large animal (porcine) model of SCI. We develop protein biomarkers of injury severity and recovery, including a prognostic model of neurological improvement at six months with an AUC of 0.91, and validate these in an independent cohort. Through cross-species proteomic analyses, we dissect evolutionarily conserved and divergent aspects of the SCI response, and establish the CSF abundance of glial fibrillary acidic protein (GFAP) as a biochemical outcome measure in both humans and pigs. Our work opens up new avenues to catalyze translation by facilitating the evaluation of novel SCI therapies, while also providing a resource from which to direct future preclinical efforts.

Each year, tens of thousands of individuals suffer an acute traumatic spinal cord injury (SCI) (1). The impact of the resulting neurological impairment on the physical, social, and vocational well-being of these individuals is profound (2). The burden on health care systems is likewise enormous (3). Decades of research in this field have generated numerous therapeutic interventions that have shown promise in preclinical studies $(4,5)$. However, among the handful that have emerged from the laboratory to be tested in the clinic, none have succeeded in demonstrating convincing neurological benefit.

In SCI, the primary traumatic insult to the spinal cord initiates a progressive cascade of secondary injury mechanisms, characterized by ischemia, excitotoxicity, apoptosis, demyelination, inflammatory cell infiltration and cytokine release, and the formation of a glial scar (6). Therapeutic approaches generally seek to curtail these responses, in order to improve neurological outcomes via neuroprotection. Interrogation of these processes in human patients is limited by the inaccessibility of spinal cord tissue, and consequently, efforts to unravel this cascade rely almost entirely on animal models (7). The underlying assumption is that the pathological responses targeted in the animal setting will be similarly modulated in the injured human spinal cord. However, the failure of efforts to translate promising treatments from animal models into the clinic raises the possibility that important biological differences exist. As such, the dearth of data describing the pathobiology of SCI in human patients represents an obstacle to the development of new therapeutic approaches.

Once a promising intervention for SCI has emerged from the laboratory, the process of establishing efficacy in human patients is exceedingly challenging. Only a handful of large-scale clinical trials in acute SCI have ever been completed, each of which has highlighted the time and tremen- 
dous resources necessary for completion (8); more recent trials have experienced significant challenges in recruitment, leading to their premature termination. At the heart of this difficulty is the singular reliance on standardized neurological assessments for patient enrollment and evaluation of efficacy. These detailed examinations are challenging or impossible to perform in a substantial fraction of acutely injured patients, due to concomitant trauma, intoxication, or sedation (9). Without a baseline evaluation, such individuals are rendered ineligible for clinical trials, severely limiting the pool of recruitable patients. Further compounding this challenge is the considerable variability in spontaneous recovery, even among patients classified similarly by the initial examination, which forces investigators to enroll large numbers of patients in order to discern treatment effects (10). With many promising new treatments vying for translation, the inability to validate them clinically presents a bottleneck to the progression of potentially effective therapies.

Clearly, for the field to move forward, new approaches are needed in the evaluation of novel therapeutics. Objective neurochemical biomarkers could catalyze a fundamental shift in the design and conduct of clinical trials for acute SCI (11). Diagnostic biomarkers of injury severity could facilitate the enrollment of acutely injured patients unable to complete a detailed neurological examination. Prognostic biomarkers of spontaneous neurological recovery could arguably have even greater utility, by reducing the number of patients needed to adequately power clinical trials. Markers that are similarly modulated in animal models, where outcome measures currently used to assess therapeutic efficacy lack a direct correlate in human, could provide a basis to prioritize therapies for translation into human trials (12).

Here, we describe a targeted proteomic analysis of CSF and serum samples serially collected over the first five days following acute SCI in a population of 111 patients. In parallel, we characterized CSF and serum samples from a porcine model of SCI, using an identical proteomic approach. In the patient population, we mine this resource to develop singleand multi-protein biomarkers of baseline injury severity and neurological recovery at six months post-injury, and validate these in an independent cohort, demonstrating highly accurate patient stratification and prognostication. Through comparative proteomic analyses, we establish both conserved biological outcomes and species-specific responses between human SCI and a large animal model, including the discovery of glial fibrillary acidic protein (GFAP) as a cross-species outcome measure. With a total of 1,329 samples analyzed, this biobank defines an unprecedented opportunity to interrogate the biology of acute traumatic SCI.

\section{Results}

Overview of study cohorts. A total of 111 individuals sustaining an acute SCI were recruited through a multicenter prospective observational trial. Patients underwent a neurological examination at baseline, and again at six months postinjury to determine the extent of neurological improvement. Clinical characteristics are provided in Table S1. CSF and serum samples were collected serially over the first five days post-injury from all patients, and were additionally obtained from 21 uninjured patients who served as negative controls. In total, 910 samples were collected and subjected to proteomic profiling, including 450 from the CSF and 460 from the serum, with between 63-100 samples from each biofluid collected at each timepoint (Fig. 1A).

In parallel, we conducted an experimental study in our previously described porcine model of traumatic SCI (13). The pig was selected on the basis of its anatomical and immunological similarities to human (14), in particular with respect to the dimensions of the spinal canal, which permit serial CSF collection through indwelling intrathecal ports (Fig. 1A-B) (15). A total of 28 pigs received contusion SCIs of three different severities (mild, moderate, or severe; 9-10 pigs per group), and an additional 15 pigs received sham laminectomies (Fig. 1B). CSF and serum samples were collected 15 minutes prior to injury, and serially over six timepoints between $12 \mathrm{~h}$ and 12 weeks post-injury. Hindlimb neurological recovery was assessed weekly in all animals until 12 weeks, at which point animals were euthanized and spinal cords were collected for histological analysis (Fig. S1C-H). In total, 419 samples were profiled from the pig study, including 204 from the CSF and 215 from the serum.

Development of targeted proteomic assays for CSF and serum. Accurate measurement of protein abundance in the CSF and serum is highly challenging, owing to the complexity and dynamic range of protein concentrations in these biofluids. In order to achieve sensitive and accurate protein quantitation, we designed targeted mass spectrometric assays based on multiple reaction monitoring (MRM) in the serum and parallel reaction monitoring (PRM) in the CSF. Target proteins were selected on the basis of an extensive literature review, in conjunction with discovery proteomic analyses of human CSF. We subsequently developed new PRM assays for 334 peptides, targeting 325 distinct CSF proteins, which in combination with 270 previously described MRM assays $(16,17)$ afforded coverage of 491 proteins (Table S2). Gene Ontology (GO) terms enriched among proteins targeted by synthetic peptides reflected immunological and inflammatory pathways, cytoskeletal and secreted proteins, and coagulation (Fig. 1C). Isotopically labeled synthetic peptides were spiked into all samples at defined concentrations, allowing direct comparison of protein abundance across the study cohort. The complete dataset of CSF and serum protein abundance data from both species is provided in Table S3.

Proteomic portraits of $\mathrm{SCl}$ across tissues and species. To obtain a global overview of the dataset, we first performed principal component analysis (PCA) of the human cohort. Samples separated on the first principal component by timepoint, rather than clinical severity, in both biofluids, suggesting that time post-injury is the primary driver of variation in protein abundance following acute SCI (Fig. 1D and Fig. S2A-B). Similar trends were apparent in analyses of the pig samples (Fig. S2C-D).

To more formally quantify these trends, we constructed 
bioRxiv preprint doi: https://doi.org/10.1101/2021.01.27.428528; this version posted January 28, 2021. The copyright holder for this preprint (which was not certified by peer review) is the author/funder, who has granted bioRxiv a license to display the preprint in perpetuity. It is made available under aCC-BY-NC-ND 4.0 International license.

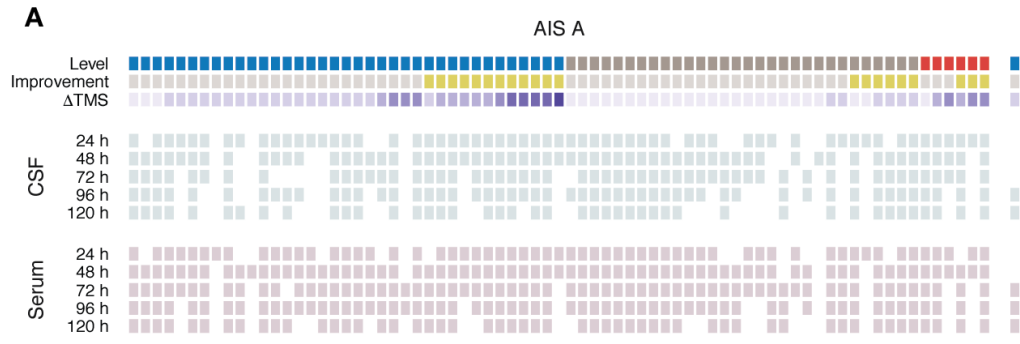

B
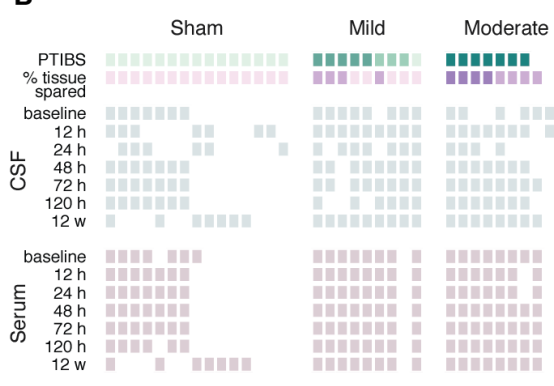

D
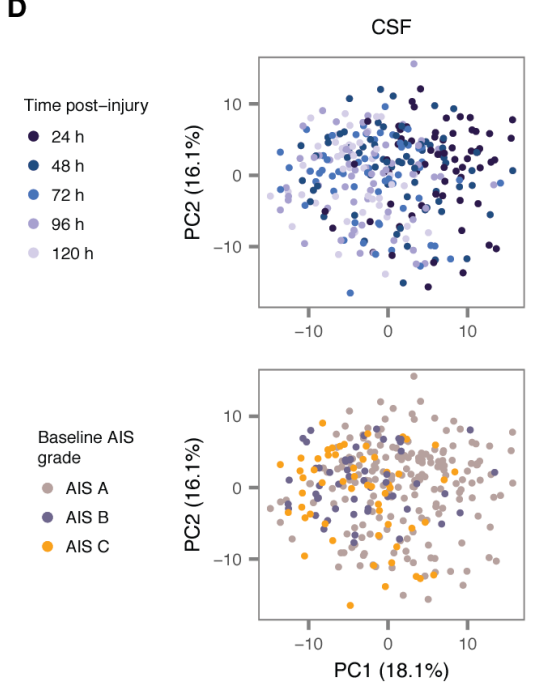

AIS B

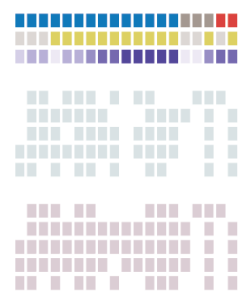

C
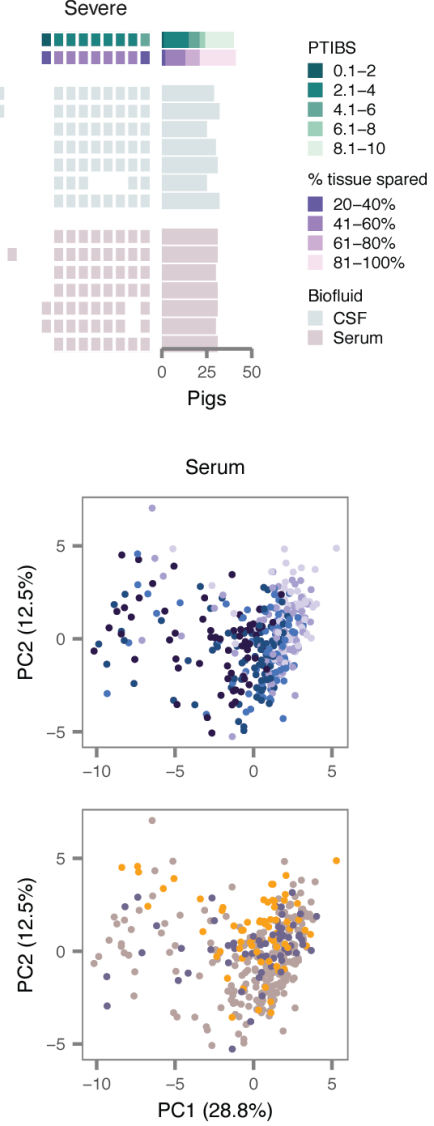

E
AIS C
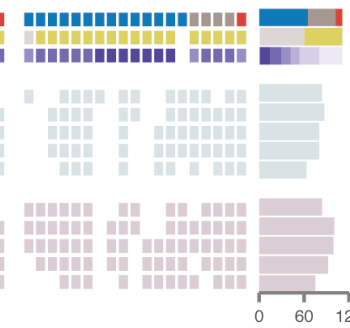
Pat 120 CSF
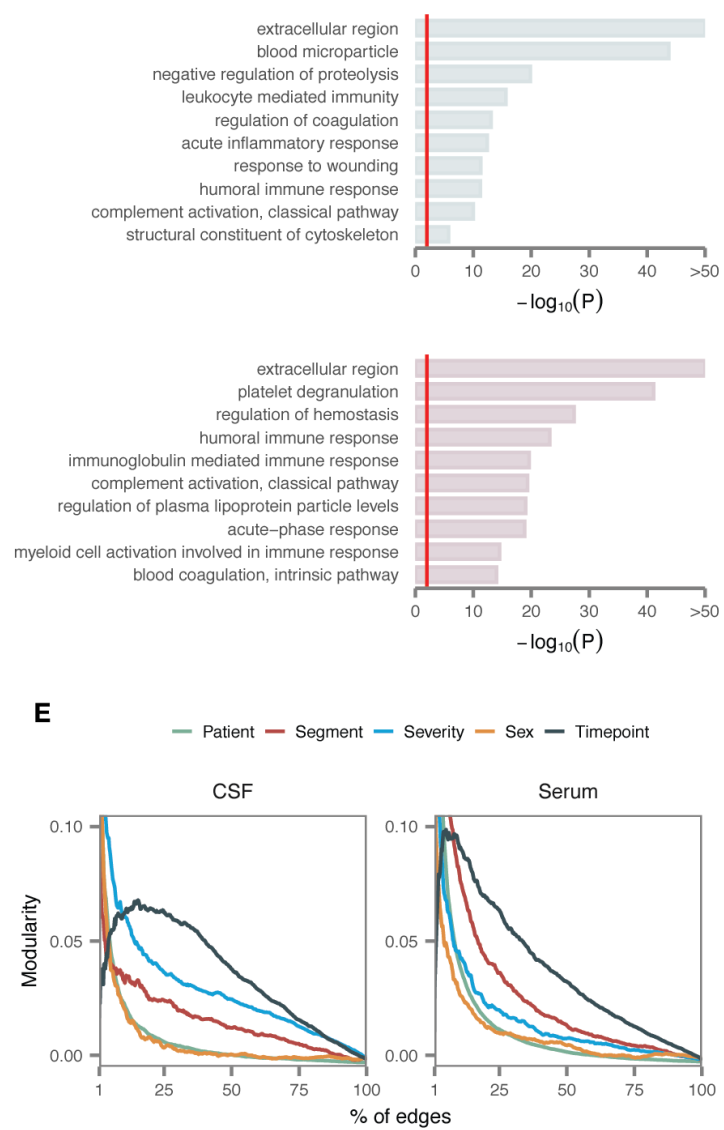

Fig. 1: Targeted proteomic profiles of CSF and serum in human and pig SCI.

(A) Overview of the human cohort ( $n=111$ patients), including key clinical measures (level of injury, AIS conversion, and change in TMS at six months post-injury), top, and sample collection at each of five timepoints in the CSF, middle, and serum, bottom.

(B) Overview of the pig cohort ( $n=43$ animals), including key experimental outcomes (PTIBS score at 12 weeks post-injury, percentage of histological tissue sparing), top, and sample collection at each of seven timepoints in the CSF, middle, and serum, bottom.

(C) GO enrichment analysis of proteins targeted by synthetic peptides in the CSF, top, and serum, bottom. Red line shows $1 \%$ FDR.

(D) PCA of human CSF and serum proteomes, with samples colored by time post-injury, top, or baseline AIS grade, bottom.

(E) Modularity analysis of CSF and serum proteomes with samples grouped by patient, level of injury (cervical, thoracic, or lumbar spinal cord), injury severity (baseline AIS grade), sex, or time post-injury. Modularity is shown as a function of the number of edges between samples used to construct the network, as a percentage of the total number of possible edges.

networks in both the serum and CSF, in which nodes corresponded to samples and edges were drawn between pairs of samples with correlated protein abundance, and carried out a modularity analysis of each network (18). Grouping samples by timepoint consistently yielded higher modularity than grouping by injury severity, confirming the trends observed visually by PCA (Fig. 1E). Interestingly, in the serum, grouping by the injured spinal segment also yielded high modularity, suggesting the neurological level of injury shapes patterns of serum protein abundance within timepoints.

Profound proteomic alterations in acute SCl. To date, interrogation of the molecular alterations that follow acute SCI has relied almost entirely on rodent models (19). Our large patient cohort provides an opportunity to define changes in the CSF and serum proteome of human SCI patients at a scale that has not previously been possible. We therefore first sought to characterize differential protein abundance following acute SCI (Table S4). 
A

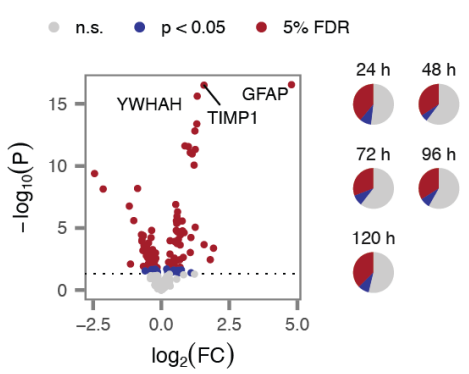

$\mathbf{F}$

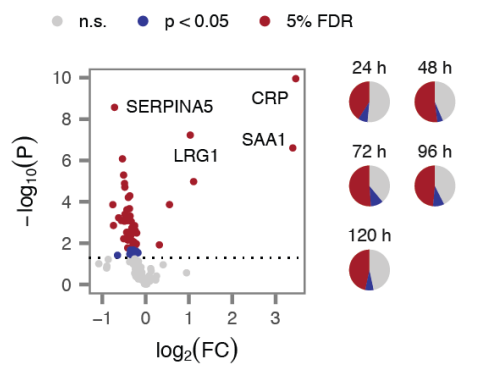

B

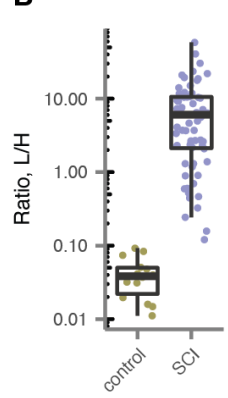

G

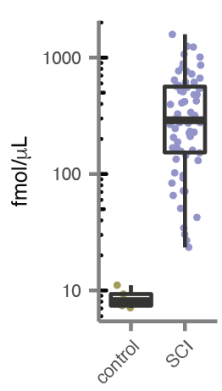

C

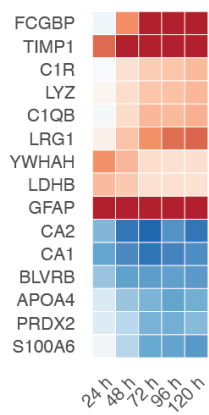

H

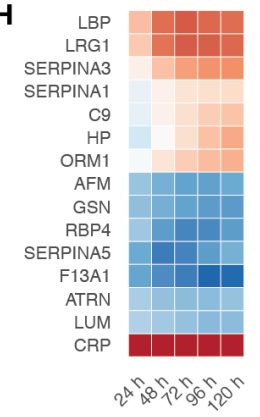

D

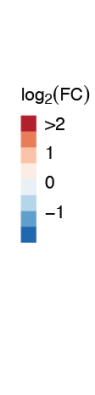

$$
\text { I }
$$

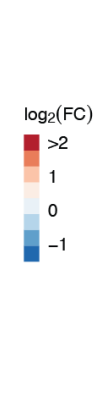

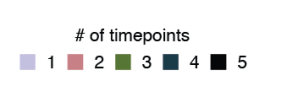

E
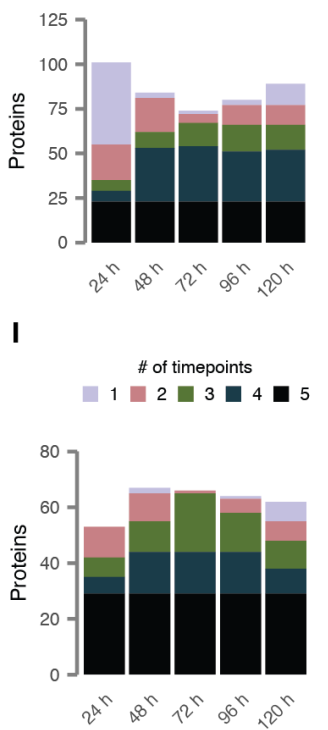

Jaccard index

0

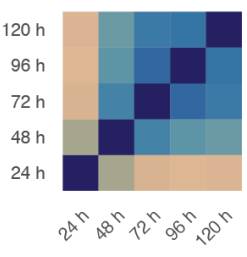

$\mathbf{J}$
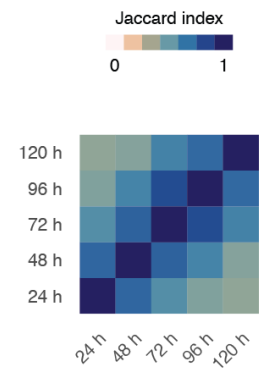

Fig. 2: Profound alterations of the CSF and serum proteomes in acute SCl.

(A) Volcano plot of differential protein abundance at $24 \mathrm{~h}$ post-injury in CSF samples from patients with acute SCl compared to uninjured controls.

(B) Abundance of GFAP in CSF samples from acute SCI patients and uninjured controls.

(C) Time courses of differential protein abundance (log-fold change, relative to uninjured controls) over the first five days post-injury for fifteen of the most profoundly altered CSF proteins.

(D) Number of differentially expressed CSF proteins at each of the first five days post-injury in acute SCl patients, grouped by the number of timepoints at which each protein was found to be differentially expressed.

(E) Similarity of proteome alterations between all possible pairs of timepoints, as quantified by the Jaccard index between the differentially expressed proteins at each timepoint.

(F) As in (A), but showing differential protein abundance in the serum at $24 \mathrm{~h}$ post-injury.

(G) Abundance of CRP in serum samples from acute SCI patients and uninjured controls.

$(\mathrm{H}-\mathrm{J})$ As in (C-E), but showing serum proteins.

In the CSF, SCI caused profound changes in protein abundance. At $24 \mathrm{~h}$ post-injury, $39 \%$ of targeted proteins displayed statistically significant differences relative to uninjured controls, at a 5\% false discovery rate (FDR; Fig. 2A, left, and Fig. S3A). Similar proportions of proteins were differentially expressed (DE) between $48 \mathrm{~h}$ and $120 \mathrm{~h}$ (Fig. 2A, right). Many displayed dramatic alterations; for instance, the abundance of GFAP in the CSF differed by 25 -fold between SCI patients and controls (Fig. 2B).

Although a handful of the most significant associations were reproduced across all five timepoints, DE proteins displayed varying temporal patterns of up- or downregulation (Fig. 2C and Fig. S3B). For instance, GFAP was maximally upregulated immediately after injury, whereas complement proteins exhibited a delayed increase in abundance. Moreover, although most DE proteins were identified at a minimum of two adjacent timepoints, a substantial proportion were uniquely identified within $24 \mathrm{~h}$ of the initial injury (Fig. 2D). Using the Jaccard index to quantify the overlap in DE proteins over each of the first five days post-injury, the $24 \mathrm{~h}$ timepoint emerged as a clear outlier (Fig. 2E). These observations suggest that a distinct set of pathophysiological processes are active in the spinal cord parenchyma during the most acute phase of the response to SCI.

Similarly marked changes were observed in the serum proteome after SCI, with $41-52 \%$ of proteins DE in SCI patients over the five-day time course (Fig. 2F and Fig. S3C). Acute-phase reactants such as C-reactive protein (CRP; Fig. 2G) were among the most strongly altered proteins. However, a less dramatic temporal course was apparent in the serum (Fig. 2H and Fig. S3D): most DE proteins were shared between adjacent timepoints, and the $24 \mathrm{~h}$ timepoint was not an obvious outlier (Fig. 2I-J). These results suggest the serum proteome reflects systemic responses to SCI that develop over longer timescales than those occurring within the central nervous system itself.

A unique aspect of our dataset is its time course design, whereby samples were collected serially from acute SCI patients over the first five days post-injury. In univariate analyses, nearly all proteins exhibited significant differences in abundance over this time course (Fig. S3E). To better understand the pathophysiological responses that are activated over the first five days after acute human SCI, we applied $k$-means consensus clustering (20) to identify modules of temporally co-regulated proteins. Seven such modules were identified in each biofluid (Fig. S4A-D). These included groups of proteins that were up- or down-regulated immediately after injury but had returned to baseline by five days, as well as groups that displayed more delayed patterns of up- and downregulation, or which were up- or downregulated for the entire 
time course (Fig. S4E-H). Analysis of enriched GO terms suggested functional correlates of each module (Fig. S4I-J). Taken together, these analyses provide an initial description of the temporal profile of molecular changes in human CSF and serum following acute SCI.

Univariate analysis identifies protein biomarkers of $\mathrm{SCl}$ severity and recovery. Next, we sought to identify individual proteins whose abundance in the serum or CSF was associated with baseline injury severity, as quantified by the baseline AIS grade, or neurological recovery, as quantified either by the change in total motor score ( $\Delta$ TMS) or AIS grade improvement at six months post-injury (Table S5). We initially focused on samples collected at $24 \mathrm{~h}$. At this timepoint, a total of 23 proteins were associated with baseline AIS grade in the CSF, all of which were more abundant in patients with more severe injuries (Fig. 3A); the most statistically significant of these associations was to GFAP (Fig. 3B). Fourteen CSF proteins were significantly associated with $\triangle$ TMS (Fig. 3C), of which eleven were also associated with baseline AIS grade, including GFAP (Fig. 3D). After correction for multiple hypothesis testing, no proteins were associated with AIS grade improvement (Fig. 3E). In parallel analyses of serum samples collected at $24 \mathrm{~h}$, only a single association was identified, between coagulation factor F11 (F11) and $\Delta$ TMS.

Given the dynamic temporal patterns of protein abundance observed in both biofluids, we subsequently repeated these analyses over each timepoint between $48 \mathrm{~h}$ and $120 \mathrm{~h}$. In the CSF, a total of 106 proteins were significantly associated with injury severity or neurological recovery within at least one timepoint (Fig. S5A-C). We searched specifically for proteins with recurrent associations, spanning multiple timepoints or clinical outcomes, reasoning that these would be substantially less likely to represent spurious hits, and identified a total of 59 proteins with at least two statistically significant associations to injury severity or recovery (Fig. 3F). Among these, GFAP emerged as the most robust marker, with ten significant associations across all timepoints (Fig. 3H). The number of significant associations peaked at $48 \mathrm{~h}$ and subsequently declined, with none identified by 120 h (Fig. 3H). Associations to baseline AIS grade and change in TMS largely overlapped, but AIS grade improvement was reflected by a distinct proteomic signature (Fig. 3I).

We then carried out a parallel analysis of recurrently associated proteins in the serum (Fig. S5D-F). Despite the dearth of associations at $24 \mathrm{~h}$ post-injury, the serum proteome was substantially more informative with respect to clinical outcomes at later timepoints. A total of 24 proteins exhibited two or more statistically significant associations (Fig. 3G). As in the CSF, the number of associations to clinical outcomes peaked at $48 \mathrm{~h}$, but a subset of serum proteins carried diagnostic or prognostic value as late as $120 \mathrm{~h}$ (Fig. 3J). Moreover, as in the CSF, there was substantial overlap between proteins associated with neurological recovery or baseline severity (Fig. 3K).

Together, these results define dozens of CSF and serum protein biomarkers with recurrent associations to injury severity or recovery over the first five days post-injury, and suggest that protein abundance at $48 \mathrm{~h}$ generally carries the greatest prognostic value.

Machine learning defines highly accurate multi-protein diagnostics. Next, we sought to optimize the accuracy of patient stratification or prognostication by combining diagnostic or prognostic information across multiple proteins simultaneously, through multivariate analyses. To this end, we developed a comprehensive machine-learning pipeline, implementing a total of 22 different classification and regression models. We then applied this pipeline to CSF and serum proteomics data from each timepoint.

We first directed our machine-learning pipeline to develop multi-protein diagnostic models of baseline AIS grade. Models trained on CSF protein concentrations at $24 \mathrm{~h}$ or $48 \mathrm{~h}$ both achieved good accuracy in fivefold cross-validation ( $81 \%$ and $82 \%$, respectively; Fig. 4A). However, the balanced accuracy, which adjusts for differences in the prevalence of each AIS grade, was substantially higher at $48 \mathrm{~h}(72 \%$ vs. $65 \%$; Fig. S6A). Closer inspection suggested that both models had difficulty correctly identifying AIS B patients (Fig. 4B and Fig. S6B). Serum models were generally less accurate (Fig. 4A, Fig. S6A and C). Although the severity of the injury is likely to be clinically apparent by $48 \mathrm{~h}$ in individuals able to perform a baseline neurological exam, a substantial proportion of patients remain poorly examinable up to $72 \mathrm{~h}$ postinjury, due to intubation and sedation following urgent surgical intervention. These patients would conceivably be candidates for emerging therapies delivered at sub-acute timepoints, suggesting a diagnostic tool based on CSF protein abundance at $48 \mathrm{~h}$ could have substantial clinical utility.

Motivated by the observation that our diagnostic models struggled to differentiate intermediate injury severities, we also asked whether we could specifically discriminate AIS A from AIS B or C patients. Indeed, CSF models demonstrated strong performance in identifying AIS A patients as early as $24 \mathrm{~h}$, achieving a maximum AUC of 0.82 and an accuracy of 85\% (Fig. 4C-E and Fig. S6D). Performance was only slightly poorer in the serum (Fig. 4C-D). These findings suggest the possibility of an acute diagnostic test to specifically identify the subset of patients in whom the likelihood of spontaneous recovery is lowest.

Multi-protein biomarkers predict neurological improvement at six months post-injury. Next, we applied the same machine-learning pipeline to develop multi-protein models capable of prognosticating ultimate neurological recovery. With respect to $\triangle \mathrm{TMS}$, the best performance was achieved by a model trained on the CSF proteome at $48 \mathrm{~h}$, which achieved a coefficient of determination $\left(\mathrm{r}^{2}\right.$ score) of 0.51 (Fig. S6E-F). However, performance was poorer for CSF models at $24 \mathrm{~h}$, and in the serum at either timepoint. Previous studies have defined $\triangle \mathrm{TMS}$ beyond a prespecified threshold, typically 6-7 points, as a primary outcome $(21,22)$, and consequently we investigated whether better accuracy could be achieved in predicting a $\triangle$ TMS of 7 or greater. Indeed, we found that serum models achieved an AUC of 0.83 and an accuracy of $78 \%$ at $24 \mathrm{~h}$ on this task (Fig. S6G-I). Thus, while 
bioRxiv preprint doi: https://doi.org/10.1101/2021.01.27.428528; this version posted January 28, 2021. The copyright holder for this preprint (which was not certified by peer review) is the author/funder, who has granted bioRxiv a license to display the preprint in perpetuity. It is made available under aCC-BY-NC-ND 4.0 International license.

A

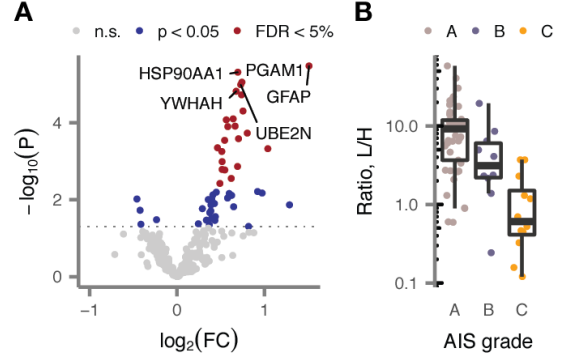

C

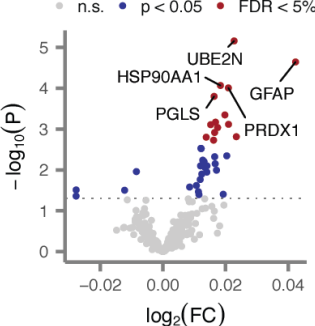

D

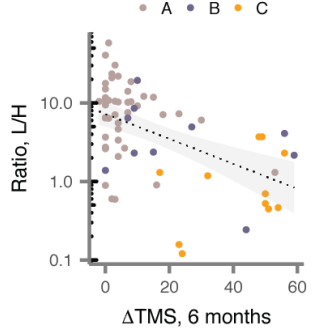

E

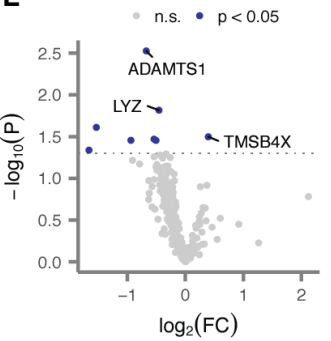

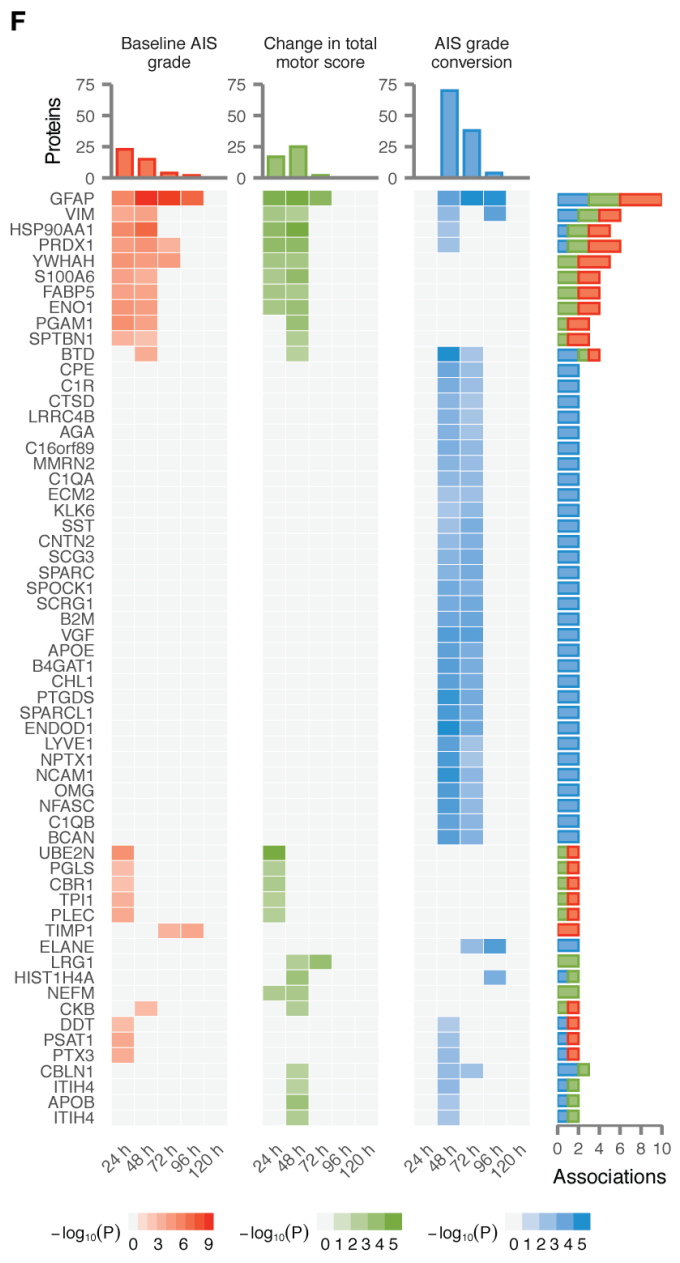

G

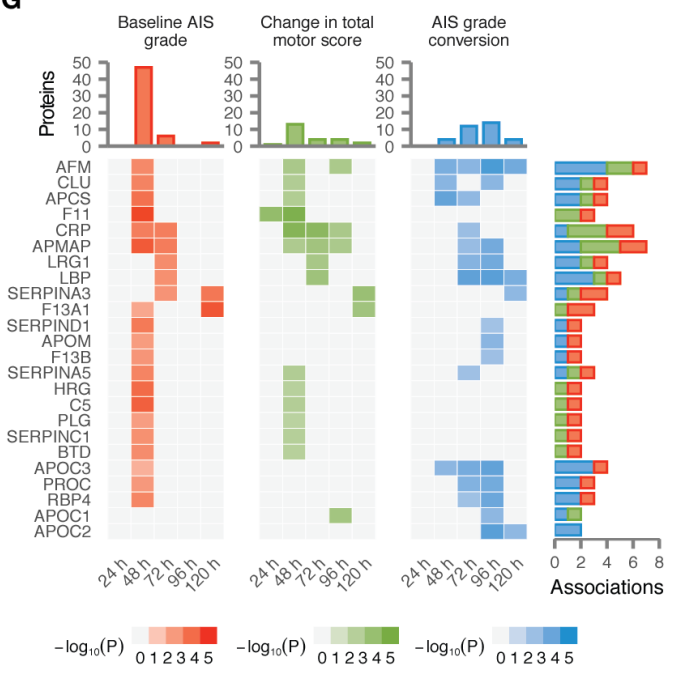

Baseline AIS grade $\square$ Change in total motor score $\square$ AIS grade conversion

H
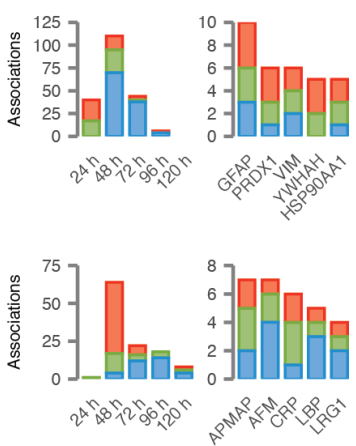

I
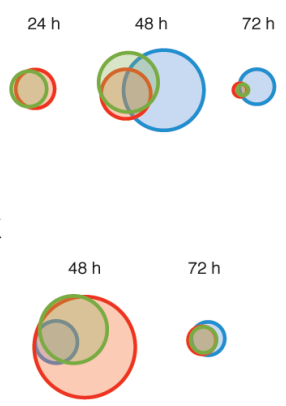

Fig. 3: Univariate protein biomarkers of $\mathrm{SCl}$ severity and recovery.

(A) Volcano plot of differential protein abundance as a function of injury severity, as measured by the baseline AIS grade, in CSF samples at $24 \mathrm{~h}$ post-injury.

(B) Abundance of GFAP in CSF samples from acute SCI patients, stratified by baseline AIS grade.

(C) Volcano plot of differential protein abundance as a function of neurological recovery, as measured by the change in TMS at six months post-injury, in CSF samples at $24 \mathrm{~h}$ post-injury.

(D) Abundance of GFAP in CSF samples from acute SCl patients, stratified by change in TMS at six months post-injury.

(E) Volcano plot of differential protein abundance as a function of neurological recovery, as measured by AIS grade improvement over baseline at six months post-injury, in CSF samples at $24 \mathrm{~h}$ post-injury.

(F) Statistical significance of associations between CSF protein abundance and three clinical outcomes over the first five days post-injury for 59 proteins with two or more significant associations. Grey squares indicate associations that were not significant after correction for multiple hypothesis testing.

(G) As in (F), but for 24 serum proteins with two or more significant associations.

(H) Number of statistically significant associations between CSF protein abundance and three clinical outcomes per timepoint, left, and for the five CSF proteins with the most recurrent associations, right.

(I) Overlap between CSF proteins significantly associated with three clinical outcomes at $24 \mathrm{~h}, 48 \mathrm{~h}$, and $72 \mathrm{~h}$ post-injury.

(J) As in $(\mathrm{H})$, but for serum proteins.

(K) As in (I), but for serum proteins at $48 \mathrm{~h}$ and $72 \mathrm{~h}$.

predicting the exact magnitude of the change in TMS is challenging, predicting whether there will be a clinically mean- ingful improvement can be achieved with reasonably good accuracy. 


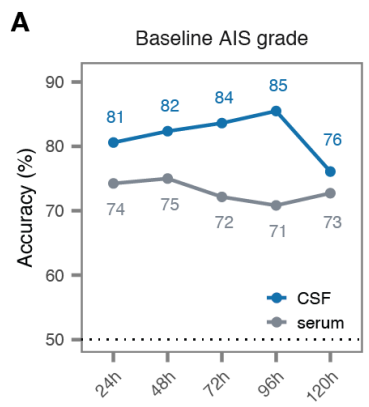

B

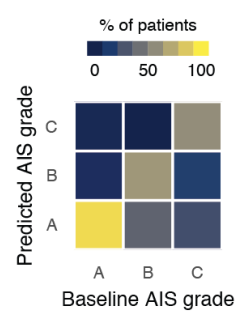

C

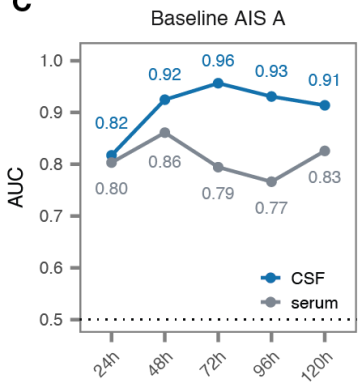

D

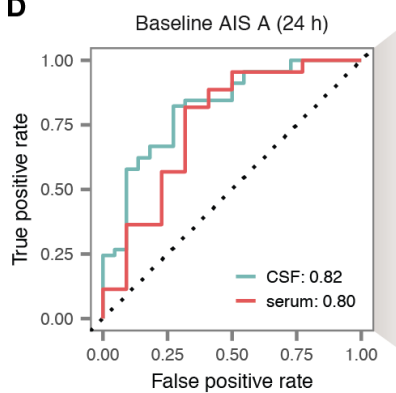

E Predicted AIS grade
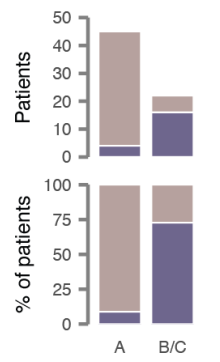

Baseline AIS grade
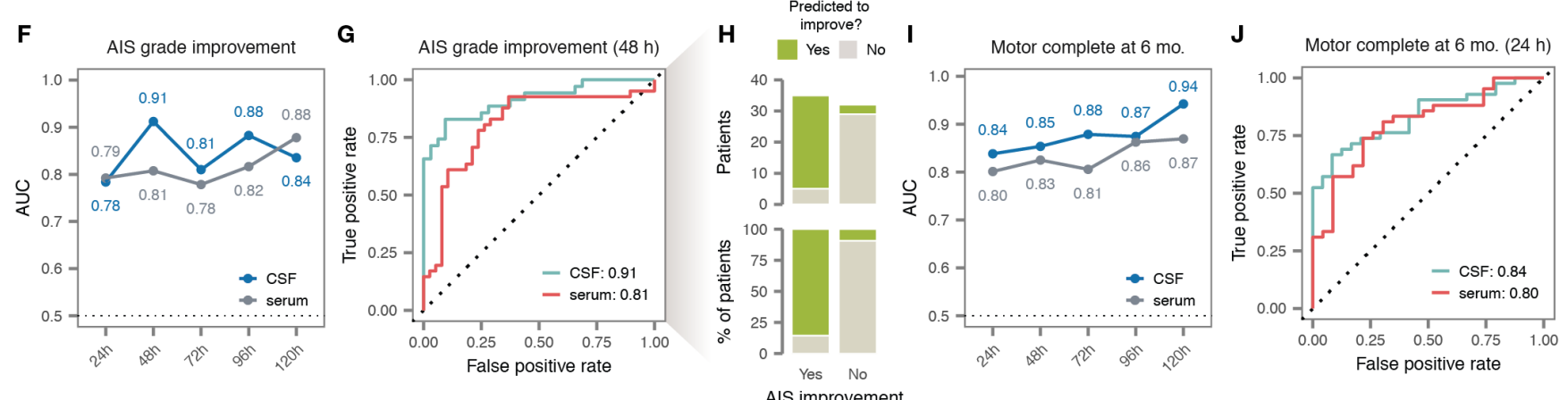

Fig. 4: Multivariate protein biomarkers of $\mathrm{SCl}$ severity and recovery.

(A) Cross-validation accuracy of multivariate diagnostic models trained to stratify patients by baseline AIS grade, at timepoints between 24 and $120 \mathrm{~h}$ post-injury.

(B) Confusion matrix of the best CSF diagnostic model of baseline AIS grade at $48 \mathrm{~h}$ post-injury.

(C) Cross-validation AUC of multivariate diagnostic models trained to discern patients with a baseline AIS grade of A, at timepoints between 24 and 120 h post-injury.

(D) ROC curves of the best CSF and serum diagnostic models at $24 \mathrm{~h}$ post-injury.

(E) Predictions made by the best CSF diagnostic model at $24 \mathrm{~h}$ post-injury.

(F) Cross-validation AUC of multivariate prognostic models trained to predict improvement in AIS grade at six months post-injury, relative to baseline, at timepoints between 24 and $120 \mathrm{~h}$ post-injury.

(G) ROC curves of the best CSF and serum prognostic models of AIS grade improvement at $48 \mathrm{~h}$ post-injury.

(H) Predictions made by the best CSF prognostic model at $48 \mathrm{~h}$ post-injury.

(I) Cross-validation AUC of multivariate prognostic models trained to predict motor complete vs. incomplete injury at six months, at timepoints between 24 and $120 \mathrm{~h}$ post-injury.

(J) ROC curves of the best CSF and serum prognostic models of motor complete vs. incomplete injury at $24 \mathrm{~h}$ post-injury.

We also sought to predict neurological recovery as defined by improvement in the AIS grade, another measure that has widely been used as a primary endpoint in clinical trials $(23,24)$ (Fig. 4F and Fig. S6J). The best-performing models made use of CSF proteomics data at $48 \mathrm{~h}$ post-injury, achieving an exceptionally high AUC of 0.91 and an accuracy of $88 \%$ (Fig. 4G-H). This performance suggests the possibility of highly accurate identification of patients likely to demonstrate spontaneous neurological improvement, with implications for both the design of clinical trials and acute patient management.

In view of these successes, we further evaluated the possibility of directly prognosticating neurological impairment at six months. Prediction of six-month AIS grade was not substantially better than random expectation (Fig. S6K). However, we found that multi-protein models could reliably distinguish motor complete vs. incomplete injuries at six months (that is, a six-month AIS grade of A/B vs. C/D; Fig. 4I and Fig. S6L). At $24 \mathrm{~h}$, the best serum model achieved an AUC of 0.80 and an accuracy of $80 \%$ (Fig. 4J and Fig.
S6M).

Taken together, these results suggest it is possible to predict much of the observed variation in neurological recovery at six months post-injury on the basis of protein abundance in acutely collected CSF and serum samples.

Validation of single- and multi-protein biomarkers in an independent clinical cohort. Having established both singleand multi-protein biomarkers of SCI severity and recovery, we next sought to validate these in an independent clinical cohort. Samples from the validation cohort $(n=20$ patients) were processed separately from the discovery cohort and blinded to investigators until after finalization of all statistical analyses. A large fraction of the alterations following acute SCI were reproduced within each biofluid and timepoint, and effect sizes were highly correlated between cohorts $(r \geq 0.90$; Fig. 5A-D and Fig. S7A-B). A total of 28 associations to injury severity or recovery were reproduced at $5 \%$ FDR, with a further 30 nominally significant (Fig. 5E-F). In the CSF, GFAP again stood out as the most promising candidate, with six associations validated at nominal significance 
bioRxiv preprint doi: https://doi.org/10.1101/2021.01.27.428528; this version posted January 28, 2021. The copyright holder for this preprint (which was not certified by peer review) is the author/funder, who has granted bioRxiv a license to display the preprint in perpetuity. It is made available under aCC-BY-NC-ND 4.0 International license.

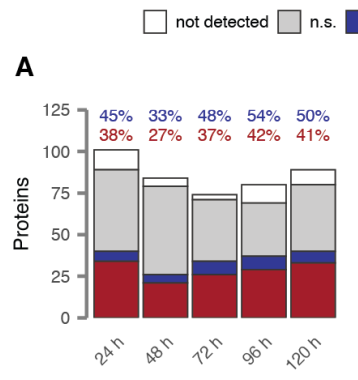

C

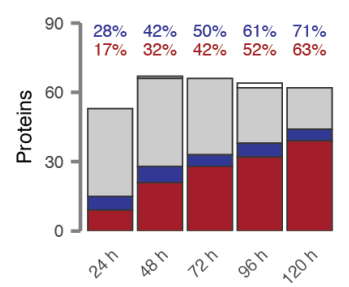

D
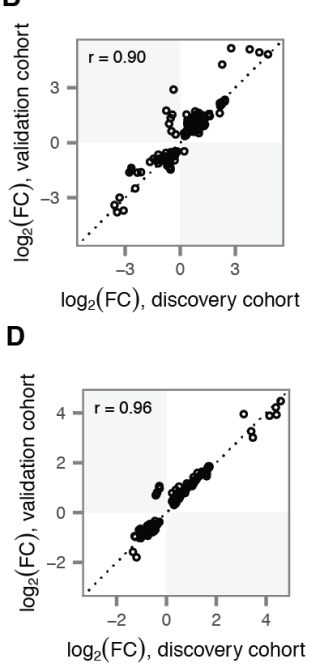

$\mathbf{F}$

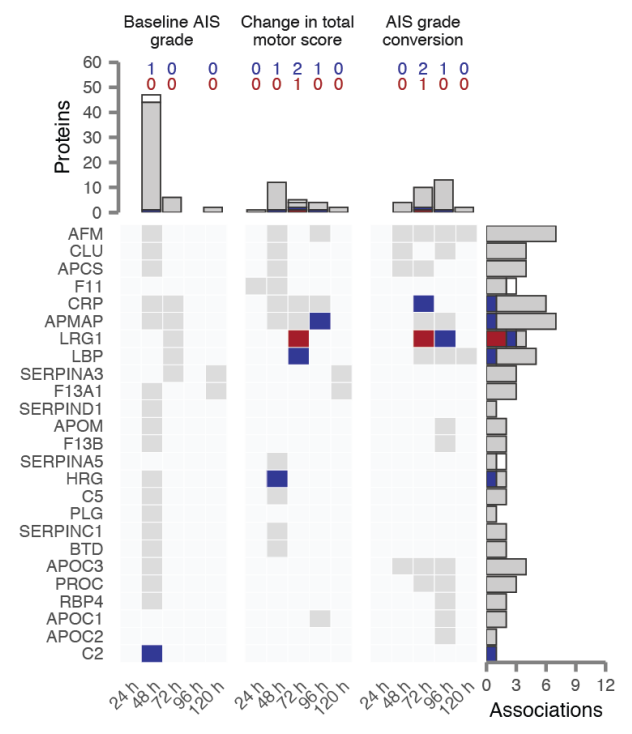

E

E

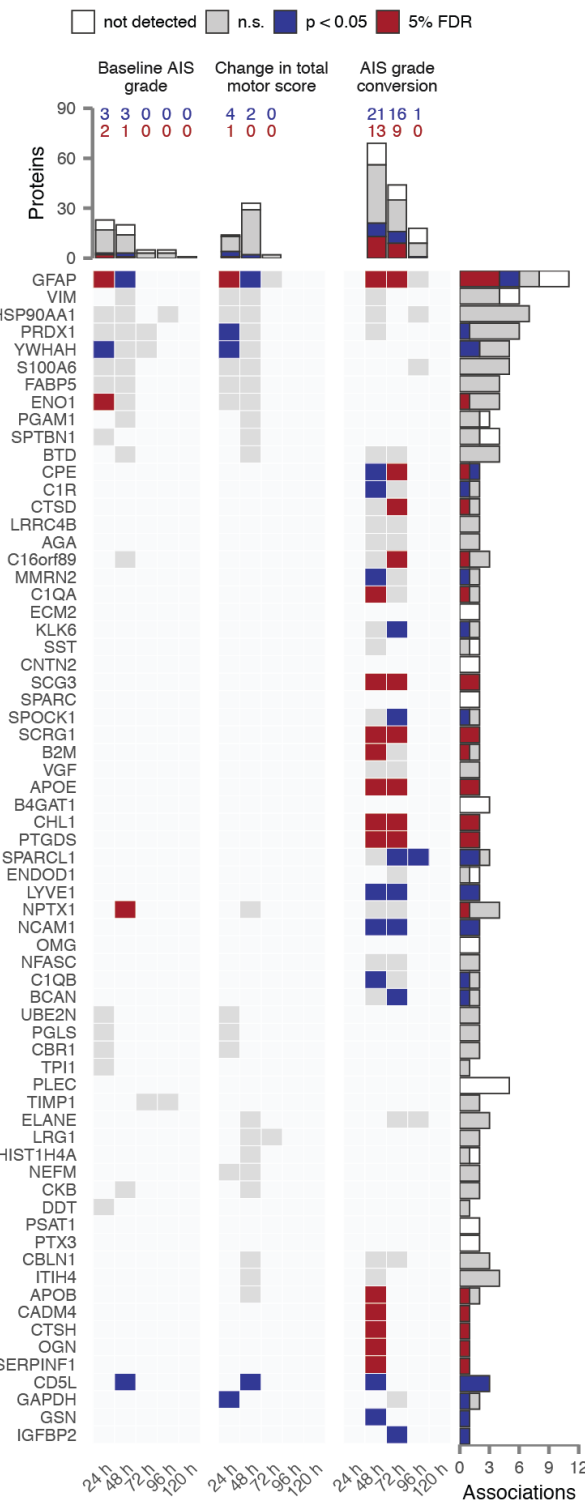

G
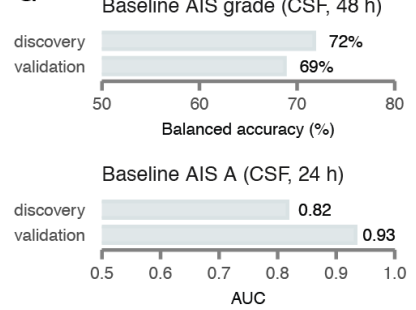

Six-month $\triangle T M S(C S F, 48 h)$
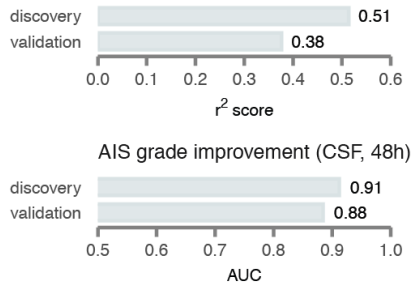

H
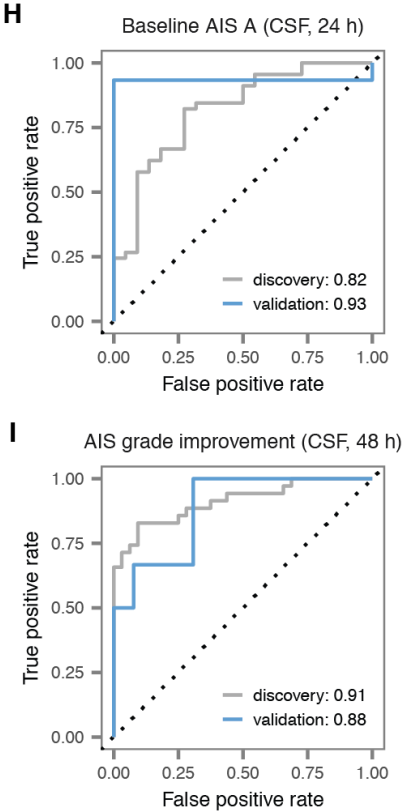

Fig. 5: Validation of univariate and multivariate biomarkers in an independent cohort.

(A) Proportion of univariate alterations in CSF protein abundance after acute SCI that were replicated at nominal significance or after multiple hypothesis testing correction, were not significant, or were not quantified in the validation cohort.

(B) Correlation between log-fold changes between the discovery and validation cohorts for proteins with replicated alterations.

(C-D) As in (A-B), but for alterations in serum protein abundance. Cross-validation AUC of multivariate diagnostic models trained to discern patients with a baseline AIS grade of $\mathrm{A}$, at timepoints between 24 and $120 \mathrm{~h}$ post-injury.

(E) Replicated associations between CSF protein abundance and three clinical outcomes over the first five days post-injury for 59 proteins with two or more significant associations (as shown in Fig. 3F) and an additional eight proteins with a single association replicated with at least nominal significance. $(F)$ As in $(E)$, but for the 24 serum proteins with two or more significant associations (as shown in Fig. 3G) and one additional protein with a single association replicated with nominal significance.

(G) Performance of four preregistered multivariate CSF models in an independent validation cohort.

(H) ROC curves of the best CSF diagnostic model of AIS A patients at $24 \mathrm{~h}$ post-injury (as shown in Fig. 4D) in the discovery and validation cohorts.

(I) ROC curves of the best CSF prognostic models of AIS grade improvement at $48 \mathrm{~h}$ post-injury (as shown in Fig. $\mathbf{4 G}$ ) in the discovery and validation cohorts.

or better (Fig. S7C-E). In the serum, associations between LRG1 at $72 \mathrm{~h}$ and both $\triangle$ TMS and AIS grade improvement were reproduced at 5\% FDR (Fig. S7F-G).

Among the multivariate models described above, six were selected and preregistered for validation, including four CSF and two serum models. All four CSF models achieved performance comparable to that observed in the discovery co- hort (Fig. 5G); serum models, in contrast, did not demonstrate convincing accuracy (Fig. S7H). Remarkably, in the validation cohort, patients with a baseline AIS grade of A could be identified with an AUC of 0.93 from $24 \mathrm{~h} \mathrm{CSF}$ (Fig. 5H) and AIS grade improvement at six months could be predicted with an AUC of 0.88 from $48 \mathrm{~h}$ CSF (Fig. 5I). Models of baseline AIS grade and $\triangle$ TMS based on $48 \mathrm{~h}$ 
CSF also achieved good performance (Fig. S7I-J). Although not among the six preregistered models, we additionally observed that motor complete injuries at six months could be identified from $24 \mathrm{~h} \mathrm{CSF}$ with an AUC of 0.96 in the validation cohort (Fig. S7K).

Thus, through blinded evaluation in an independent cohort, enrolled and processed after the discovery cohort to emulate a prospective clinical study, we successfully validated dozens of individual proteins and four multi-protein models for patient stratification and prognostication in SCI.

Proteomic alterations in a large animal model of SCl. The vast majority of our knowledge concerning the pathophysiological responses to acute SCI has emerged from studies in animal models. Through these studies, many therapies have emerged that effectively target the secondary injury responses triggered after SCI in rodents and other species. However, the subsequent failure of these apparently promising agents in human clinical trials raises the possibility that important biological differences exist between animal models and human SCI. The difficulty of translating novel therapies is compounded by the fact that functional or anatomical outcome measures assessed in animal models, such as "hindlimb locomotor function" or "white matter sparing at the injury site", cannot be measured in humans, or may have limited relation to clinically relevant outcomes. Establishing biochemical markers that are predictive of neurological outcomes in both animal models and human patients could provide endpoints for preclinical studies that are directly informative about human SCI. We therefore sought to leverage our parallel study of SCI in a large animal model in order to identify biochemical markers of injury severity and recovery that could serve as translational linkages between species.

We first addressed whether, in a combined analysis of human and pig samples, proteomic profiles would segregate globally by species or by time post-injury, the dominant source of within-species variation. To this end, we performed PCA on a combined matrix of human and pig samples at four matching timepoints ( $24 \mathrm{~h}, 48 \mathrm{~h}, 72 \mathrm{~h}$, and $120 \mathrm{~h}$ ). Reassuringly, samples separated primarily by time post-injury, rather than by species, suggesting that divergences between species are not so pronounced as to preclude extrapolation from one organism to another (Fig. 6A). Modularity analysis quantitatively confirmed this trend (Fig. S8A). Parallel analyses yielded similar results in the serum (Fig. S8B-C).

Having established a basis for cross-species comparison, we next sought to identify differences in protein abundance between CSF and serum samples collected from injured pigs, and matching samples drawn 15 min prior to injury (Table S7). Despite the comparatively lower number of observations in pig ( $n=25-32$ samples per biofluid and timepoint), this repeated-measures design provided excellent statistical power to detect proteomic alterations in SCI, with 37-69\% of proteins DE over the first five days post-injury (Fig. 6BC and Fig. S8D-G). Several of these changes persisted until 12 weeks post-injury, providing an initial description of proteomic alterations in the chronic phase of SCI. Similarly, we performed univariate analyses of baseline severity, neurolog- ical recovery, and histological tissue sparing in the pig CSF and serum, identifying thirteen proteins with recurrent associations to experimental variables in the CSF, and four in the serum (Fig. S8H-I). The majority of these associations were detected at $12 \mathrm{~h}$, although a subset were detected over multiple timepoints (Fig. S8J-K).

We next took advantage of our parallel univariate analyses in both human and pig to directly compare protein alterations across species, focusing our analysis primarily on the CSF due to the relatively small number of associations in the serum of either species. A substantial fraction of CSF proteins were comparably modulated following SCI in both human and pig, with $14-31 \%$ of proteins DE in both species at matching timepoints (Fig. 6D-E and Fig. S9A). Accounting for incomplete power by using the $\pi_{1}$ statistic to estimate the proportion of null hypotheses (25) further increased the estimated degree of overlap, to $57-81 \%$ (Fig. S8L-M).

These data indicated that the proteomic alterations that accompany acute SCI are broadly conserved between human and pig. In contrast, markers of injury severity or recovery were more species-specific. Across all four matching timepoints, only two associations were reproduced in both species (Fig. 6E and Fig. S9B-D). Remarkably, these implicated the same protein at the same timepoint: CSF levels of GFAP at $24 \mathrm{~h}$ were correlated to both baseline injury severity and hindlimb neurological recovery in pigs (Fig. 6F and Fig. S8N). This finding immediately suggests a biochemical outcome measure with direct relevance to human injury that could be used to monitor injury progression and therapeutic response in animal studies, with direct relevance to human injury.

\section{Convergent proteomic signatures in human and porcine $\mathrm{SCl}$.}

Although univariate analyses successfully identified individual proteins altered in both human and pig SCI, we reasoned that relying on a simple overlap between DE proteins in either species could reduce our sensitivity to detect small but concordant changes. To overcome this limitation, we performed a threshold-free analysis using rank-rank hypergeometric overlap (RRHO) (26) to identify convergent proteomic signatures of acute SCI, injury severity, and recovery. We applied this method to compare all pairs of timepoints evaluated in either species, reasoning that equivalent responses may not be activated at perfectly matching timepoints between species.

We first applied RRHO analysis to compare proteomic signatures of acute SCI (Fig. 7A). As anticipated from our univariate analyses, highly significant overlap was observed between approximately matching timepoints (Fig. 7B). Surprisingly, however, there was more limited overlap between mismatched timepoints, suggesting substantial dynamic evolution in the molecular response to SCI over the first five days post-injury. The greatest overlap was observed at $24 \mathrm{~h}$ and earlier, indicating the most acute phase of the response to SCI is the most strongly conserved between species. Sub-acute and chronic phases also showed a broad alignment, with significant overlap between the human protein signature of SCI at $120 \mathrm{~h}$ and the pig signature between $72 \mathrm{~h}$ and $12 \mathrm{w}$. This 
A

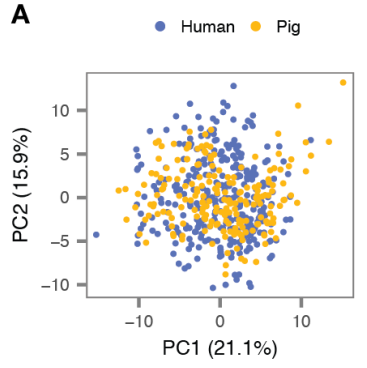

D
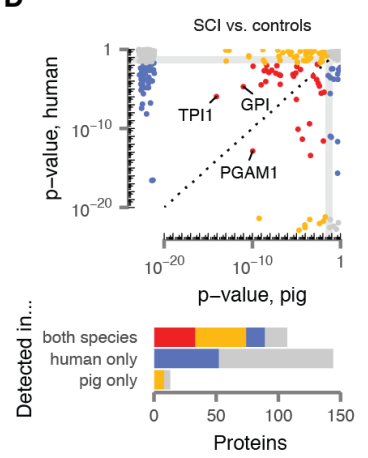

- $12 \mathrm{~h}: 48 \mathrm{~h}: 96 \mathrm{~h} \cdot 12 \mathrm{w}$

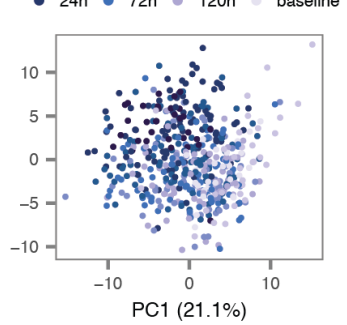

- both species - human only - pig only - n.s.

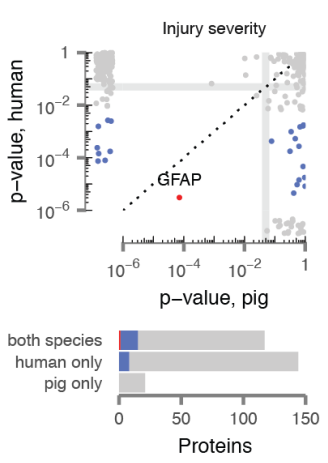

B
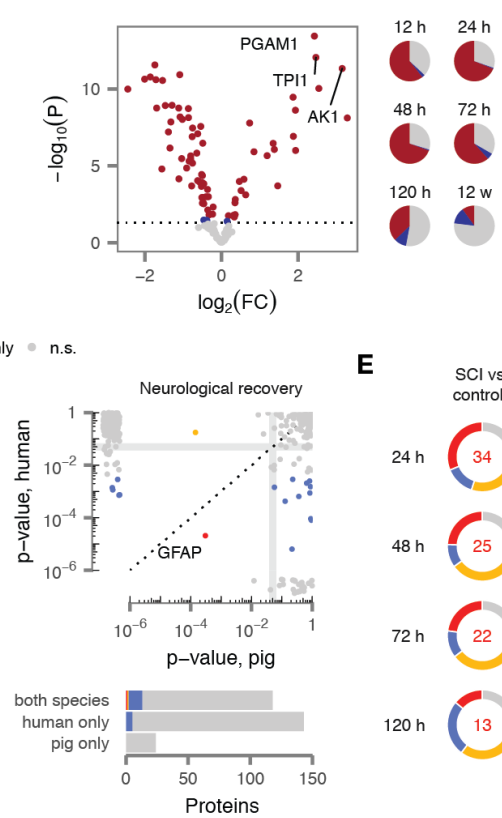

E
C
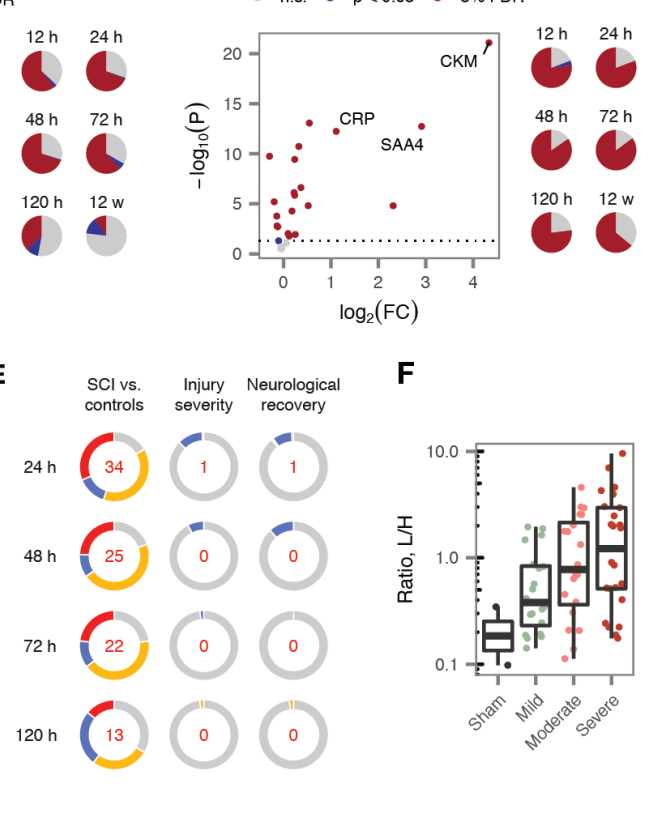

$\mathbf{F}$

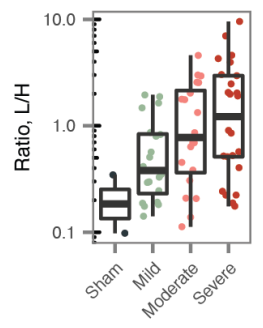

Fig. 6: Proteomic profiles of a large animal model define cross-species biomarkers of SCI.

(A) Principal component analysis of human and pig CSF proteomes, with samples colored by species, left, or time post-injury, right.

(B-C) Volcano plots of differential protein abundance at $24 \mathrm{~h}$ post-injury in CSF (B) and serum (C) samples from injured pigs, compared to samples drawn from the same pigs at baseline ( $15 \mathrm{~min}$ prior to injury). Pie charts show the proportion of differentially expressed proteins between $12 \mathrm{~h}$ and 12 w post-injury.

(D) Top, $\mathrm{p}$-values for differential protein abundance at $24 \mathrm{~h}$ in human and pig, in comparisons of individuals with acute SCl and uninjured controls, left; as a function of injury severity, middle; or as a function of neurological recovery, right. Marginal plots show $p$-values for proteins quantified in human (pig) only. Bottom, number of proteins with statistically significant differential abundance in both species, human only, pig only, or neither, among proteins quantified in both species, human only, or pig only.

(E) Proportion of human and pig proteins that are differentially abundant in both species, one species, or neither, at all four matched timepoints following acute $\mathrm{SCl}$, left; as a function of injury severity, middle; or as a function of neurological recovery, right. Inset numbers show proteins that were differentially abundant in both species.

(F) Abundance of GFAP in pig CSF samples at $24 \mathrm{~h}$ post-injury as a function of injury severity.

observation suggests that many of the molecular alterations that persist into the chronic stage of the injury have been established in human by $120 \mathrm{~h}$ post-injury.

We next applied RRHO to compare protein signatures of injury severity and neurological recovery (Fig. 7B and Fig. S10A). Broadly similar patterns to those identified for acute SCI were observed in the latter analysis, with the strongest overlap at the most acute stages of injury, and a more modest overlap at $120 \mathrm{~h}$. In contrast, no significant overlaps were detected between human and pig with respect to baseline injury severity (Fig. S10B). This finding may reflect a fundamental dissimilarity between the precisely controlled measures of injury severity employed in animal studies, and the subjective, ordinal assessments carried out in the emergency room.

\section{Conserved and divergent patterns of protein co-expression.}

Beyond comparing signatures of specific clinical outcomes, we sought to identify individual proteins or biological processes with diverging patterns of abundance across species more generally. To this end, we applied neighborhood analysis of conserved coexpression (NACC) (27). This method has the advantage of not requiring that samples from either species be precisely matched with respect to clinical outcomes or timepoints, so long as two large and diverse panels are provided.

To apply NACC, we constructed protein co-expression networks in the CSF of either species, and evaluated the degree to which proteins tended to be co-expressed with the same neighbors across species. On a global level, we observed a significantly higher degree of shared coexpression between species than random expectation $(p<$ $10^{-15}$, Brunner-Munzel test; Fig. 7C), providing further evidence for broad conservation of protein function in SCI. Using the $\pi_{1}$ statistic, we estimated that $82 \%$ of proteins are co-expressed with shared neighbors across species (Fig. 7D and Fig. S10C). Ranking individual proteins based on the strength of conservation of their co-expression neighborhood (Fig. 7E and Table S8A), we found that no individual protein exhibited a significant divergence across species.

We then performed a similar NACC analysis at the level of biological processes. Among 220 GO terms robustly quantified in both species, eight were significantly conserved, whereas nine were divergent (Fig. $7 \mathbf{F}$ and Table S8B). GO terms displaying significantly conserved co-expression were largely related to neuronal structure and function (e.g., "axon guidance", "glutamatergic synapse"). Conversely, GO terms associated with evolutionary divergence implicated immune and inflammatory processes ("immune response," "cellular 
A

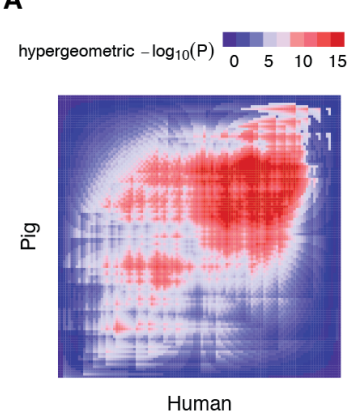

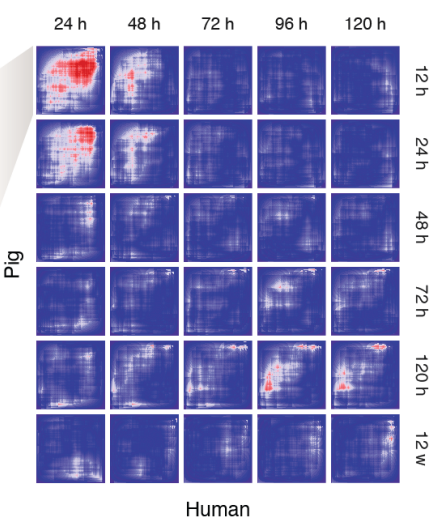

E

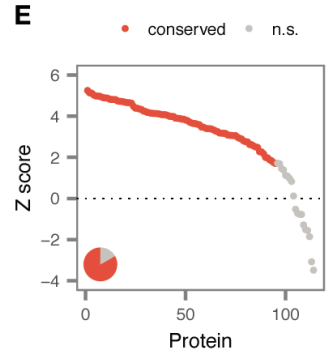

B
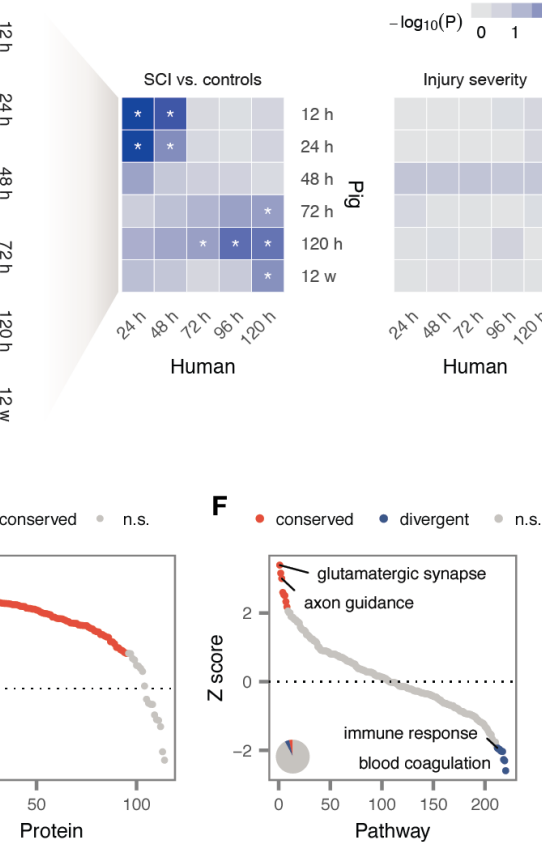

Injury severity

Protein
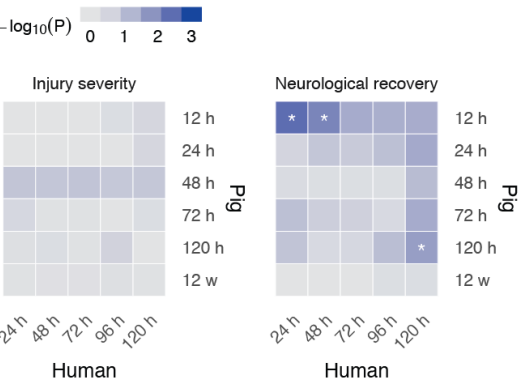

G $\quad$ Cost 34567

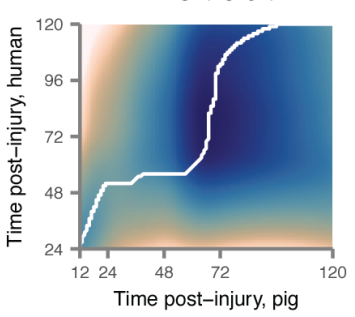

C

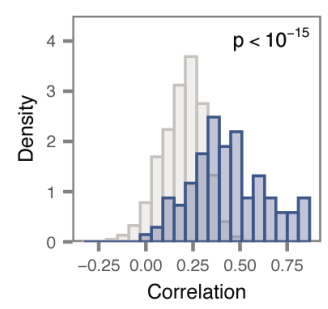

D

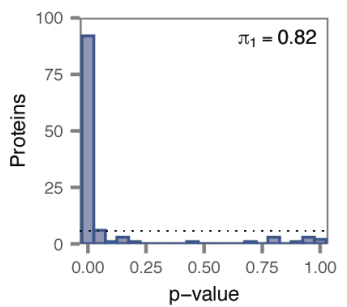


tional, and clinical research in SCI.

Over the course of several decades, small-scale studies of SCI in animal models, primarily rodents, have amassed a substantial body of understanding about the pathobiology of SCI. In contrast, direct observations of secondary injury responses in human patients have historically been rare, and limited both by sample size and the number of analytes measured (28-32). The paucity of molecular-level descriptions of human SCI presents a broad limitation for translational research in a field that relies almost entirely on rodent experimental models for the development of new therapies. In this context, our analysis of 491 proteins across a total of 844 samples from 111 acute SCI patients provides an unprecedented resource to understand the evolving molecular responses to human SCI over the first five days post-injury, both within the central nervous system and systemically. Moreover, through serial collection of both biofluids over the first five days post-injury, we characterized the temporal profile of molecular changes following acute SCI, allowing us to dissect the complex biological responses that unfold over time after traumatic injury. Strikingly, we found that the proteomic alterations during the most acute phase, up to $24 \mathrm{~h}$ post-injury, were substantially distinct from those over the subsequent four days. This observation is particularly noteworthy given that our cross-species analysis established these early responses as most strongly conserved across species, and thus reveals an evolutionarily conserved 'hyper-acute' phase of SCI.

A primary goal of our study was to establish diagnostic and prognostic biomarkers of SCI. Through univariate analyses, we identified dozens of CSF and serum proteins with recurrent associations to injury severity or recovery, among which GFAP emerged as a particularly promising candidate. We then applied a machine-learning pipeline to develop multi-protein models. Perhaps most remarkably, we established a prognostic model capable of predicting AIS grade improvement at six months from the CSF proteome at $48 \mathrm{~h}$ post-injury with an AUC of 0.91. Excellent performance was also achieved in stratifying patients by AIS grade, identifying AIS A patients, and predicting motor complete injuries at six months. We subsequently went on to validate both univariate markers and preregistered multivariate models in an independent clinical cohort, in a manner designed to rigorously emulate a prospective clinical evaluation. Previous attempts to identify biomarkers in acute SCI have generally taken place in small patient cohorts, lacked validation in an independent cohort, and in several cases conflated training and test data when reporting accuracy. The methodological rigour of our efforts to validate these markers thus goes substantially beyond what has previously been achieved in this field. The success of this effort indicates that these tools could both facilitate the conduct of clinical trials, and inform decisions about acute and rehabilitative management, setting the stage for eventual precision medicine approaches.

The degree to which widely used animal models accurately reflect the pathophysiological processes active in SCI, and human disease more generally, has been extensively debated (33-36). Through comparative proteomic analysis in a porcine model, we provide systematic molecular evidence of substantial concordance in the molecular response to SCI between species, with several orthogonal analyses converging on an estimate that $\sim 80 \%$ of proteome alterations are shared between human and pig. However, we also detected divergence in specific processes, most notably the immune response. We identified convergent proteomic signatures of neurological recovery, but not injury severity, possibly reflecting a fundamental dissimilarity between measures of severity employed in human and animal studies. Our search for conserved biological endpoints nonetheless led to the identification of GFAP as significantly correlated to both baseline severity and neurological outcome in both species. Last, our dense time-course design in either species allowed us to perform, to our knowledge, the first systematic comparison of temporal patterns in the molecular response to a disease between species. Through a direct alignment of the human and pig time courses, we identified accelerated progression of the SCI response in our pig model, with implications for the timing of drug administration or other therapeutic interventions in preclinical studies. Collectively, this body of work addresses a number of outstanding questions about the validity of animal models of SCI, and defines a biochemical outcome measure for animal studies with direct relevance to the clinical setting.

Our study employed a targeted proteomics approach to measure the abundance of 491 proteins in the CSF and serum. The definitive advantage of this approach is its ability to provide precise quantification in analytically challenging biofluids, with sensitivity comparable to antibody-based assays $(37,38)$. Moreover, unlike these assays, this approach can be readily applied to proteins for which reliable antibodies may not exist. Conversely, although our interrogation of several hundred proteins within the CSF and serum of human SCI patients far exceeds any effort reported in the literature to date, our inferences are necessarily limited to the panel of proteins targeted here. An additional limitation of our study is the requirement that subjects complete a valid neurological examination within $24 \mathrm{~h}$ of admission; the possibility of important pathophysiological differences in patients unable to perform this exam cannot be excluded. 


\section{Methods}

Clinical trial enrollment. Individuals sustaining an acute SCI were enrolled into this prospective observational study (clinicaltrials.gov: NCT01279811) at four North American sites if they met the following inclusion criteria: (1) AIS grade A, B, or C on presentation; (2) spinal injury between $\mathrm{C} 1$ and L1; and (3) the ability to provide a valid, reliable neurological examination within 24 $\mathrm{h}$ of injury. Patients were excluded if they had concomitant brain injuries or concomitant major trauma to the chest, pelvis, or extremities that required invasive intervention (e.g. chest tube, internal or external fixation), or were too sedated or intoxicated to provide a valid neurological examination. The study population was divided into two groups of consecutively enrolled patients, with the first 91 constituting the discovery cohort, and the subsequent 20 held out as a validation cohort. The uninjured control group consisted of 21 adult subjects undergoing routine lumbar decompressions and/or fusions who had no current or past history of SCI or myelopathy. The study was performed under the approval of the UBC Clinical Research Ethics Board (CREB; \#H10-01091 for the clinical trial, \#H08-00118 for normal controls).

Neurological evaluation. The severity of neurological impairment was graded according to the standards of the ISNCSCI examination, with motor scores recorded separately in the upper and lower extremities. All baseline testing and the assigning of the baseline AIS grade (A, B, or C) was conducted by research study nurses to confirm the initial examination of the patients. The baseline American Spinal Injury Association (ASIA) Impairment Scale (AIS) grade was A for 73 patients, B for 19, and C for a further 19, where AIS A denotes complete motor and sensory paralysis, AIS B denotes complete motor paralysis but some preserved sensation, and AIS C is assigned when there is some preserved motor and sensory function. The ISNCSCI examination was conducted again at six months postinjury in all but one patient, who was lost to follow-up and excluded from analyses of neurological recovery, to determine whether the AIS grade had improved and the extent of total motor score improvement.

Porcine model. Female Yucatan miniature pigs (Sus scrofa) (Sinclair Bio-resources, Columbia, MO), aged approximately 150200 days and weighing $20-30 \mathrm{~kg}$, were group-housed at a large animal facility for 5 weeks prior to surgery. Animals were blockrandomized into different injury severity groups, or a sham group. Animals in the sham group received an identical laminectomy surgery as in the injured groups, but no weight drop injury or compression to the spinal cord. Three different injury severities were induced by dropping a $50 \mathrm{~g}$ weight onto the exposed spinal cord from a height of 40,20 , or $10 \mathrm{~cm}$, followed by 5 minutes of compression with a $150 \mathrm{~g}$ weight. Surgical procedures for experimental SCI and post-operative care were as previously described $(13,39)$. Briefly, using anatomical landmarks, the T9, T10, and T11 pedicles were cannulated and instrumented with screws (SelectTM Multi Axial Screw, Medtronic, Minneapolis, MN). After the T10 laminectomy was performed, the weight drop device was rigidly secured to the pedicle screws and positioned so that the impactor would fall directly on the exposed dura and spinal cord at T10. All animal experiments were conducted in accordance with the University of British Columbia Animal Care Committee (\#A16-0311) and in strict adherence to the guidelines issued by the Canadian Council for Animal Care.

Porcine neurological evaluation. The Porcine Thoracic Injury Behavior Scale (PTIBS) was used to assess hindlimb functional recovery, as previously described (13). Briefly, four weeks prior to injury, animals were trained to walk straight at a constant speed without stopping. Baseline behavior was obtained for each animal, one week prior to surgery; five runs were recorded using three highdefinition camcorders placed $30 \mathrm{~cm}$ above the ground and behind the animals. Functional assessment resumed one week post-injury and continued once weekly for 12 weeks. The functional assessment footage was analyzed by two independent observers that were blinded to the biomechanical severity of spinal cord injury that was induced at the time of surgery. The PTIBS scale ranges from no active hindlimb movements (score 1), to normal ambulation (score 10). PTIBS scores of 1-3 are characterized by "hindlimb dragging," scores of 4-6 reflect varying degrees of "stepping" ability, and scores of 7-10 reflect varying degrees of "walking" ability.

Porcine histological evaluation. Tissue sparing was assessed by histological analysis at the end of the experiment (12 weeks postinjury), at which point animals were euthanized by sodium pentobarbital $(120 \mathrm{mg} / \mathrm{kg})$, the spinal cord harvested, post-fixed and cryoprotected as previously described (40). Subsequently, spinal cords were cut into $1 \mathrm{~cm}$ blocks centered on the site of injury, frozen on dry ice, and stored at $-80^{\circ} \mathrm{C}$. Cross-sections ( $20 \mu \mathrm{m}$ thick) were then cut using a cryostat. Sections were serially mounted onto adjacent silane-coated SuperFrost Plus slides (Fisher Scientific, Pittsburgh, $\mathrm{PA}$ ) and stored at $-80^{\circ} \mathrm{C}$. For differentiating grey and white matter, Eriochrome Cyanine R staining (EC) was performed with Neutral Red as a counterstain. EC-stained sections were examined and micrographs $(5 \times$ objective, Zeiss AxioImager M2 microscope) were taken of sections at $800 \mu \mathrm{m}$ intervals throughout the lesion site. The spinal cord outer perimeter, white matter, and gray matter were outlined, and the area of each was calculated using Zen Imaging Software (Carl Zeiss Canada Ltd., Toronto, ON, Canada). The percentages of white matter and grey matter were calculated by dividing the spared white or grey matter by the total area of the spinal cord on a given section, with the sum of the two representing spared tissue.

Sample collection. Collection of CSF samples from enrolled patients was achieved using an intrathecal catheter (Braun Medical Inc., PA), inserted before the surgical procedure in the lumbar spine at L2/3 or L3/4 using a standard aseptic technique. The catheter was advanced $15-20 \mathrm{~cm}$ from the entry point on the skin surface and kept in place for five days. Samples of 3-4 mL were drawn at the time of catheter insertion and then in the subsequent postoperative period, approximately three times per day, discarding the first $1 \mathrm{~mL}$ of CSF aspirated. For the non-SCI control group, samples were acquired during the operation after the lumbar spine had been exposed. Sample processing was performed immediately at the patient's bedside by the research study nursing team. CSF samples were centrifuged at $1,000 \mathrm{~g}$ for $10 \mathrm{~min}$. Blood samples were incubated at room temperature for $25 \mathrm{~min}$, then centrifuged at $10,000 \mathrm{~g}$ for $5 \mathrm{~min}$. CSF and serum supernatants were collected and dispersed into $200 \mu \mathrm{L}$ aliquots, then immediately frozen in an ethanol-dry ice bath and stored at $-80^{\circ} \mathrm{C}$.

Serial collection of porcine samples was performed 15 minutes prior to injury, and then again at $12 \mathrm{~h}, 24 \mathrm{~h}, 48 \mathrm{~h}, 72 \mathrm{~h}, 120 \mathrm{~h}$, and 12 w post-injury, as previously described $(15,39)$, and depicted in Fig. S1. Briefly, CSF collection was achieved using a 19 gauge epidural catheter (Braun Medical Inc., PA) inserted into the intrathecal space with the catheter tip resting approximately $8 \mathrm{~cm}$ caudal to the injury site. A total of $1 \mathrm{~mL}$ of CSF was collected and immediately centrifuged at $1,000 \mathrm{~g}$ for 10 minutes at room temperature. Serum collection was performed by inserting an $8 \mathrm{~F}$ Groshong catheter (Bard Access Systems) in the left external jugular vein. This was connected to a low volume titanium subcutaneous access port (X-port; Bard Access Systems) housed in the posterior neck region. A to- 
tal of $5 \mathrm{~mL}$ of whole blood was collected. To separate the serum portion, blood was allowed to incubate for 25 minutes at room temperature, and then centrifuged at $10,000 \mathrm{~g}$ for 5 minutes.

Targeted proteomic assays. Serum protein quantitation was achieved using an expanded and updated version of a previously described multiple reaction monitoring $(\mathrm{MRM})$ panel $(16,17)$ targeting 270 proteins. These peptides had been previously validated for their use in LC-MRM experiments following the CPTAC guidelines for assay development (41). Tryptic peptides were selected to serve as molecular surrogates for the 270 target proteins according to a series of peptide selection rules (e.g., sequence unique, devoid of oxidizable residues) and detectability, as described (17). All peptides were synthesized via Fmoc chemistry, purified through RPHPLC with subsequent assessment by MALDI-TOF-MS, and characterized via amino acid analysis (AAA) and capillary zone electrophoresis (CZE).

For CSF protein quantitation, new parallel reaction monitoring (PRM) assays targeting 325 proteins were developed for the present study. CSF protein targets were selected on the basis of (1) an extensive literature review to identify proteins previously been implicated in SCI or traumatic brain injury (TBI), and (2) discovery proteomics experiments performed on undepleted CSF from injured patients and uninjured controls. Peptide targets from these proteins were selected using PeptidePicker (42) on the basis of detectability by mass spectrometry, digestion efficiency, lack of potential modifications, lack of potential interferences, and conservation between human and pig. A total of 500 isotopically labeled peptides, containing either ${ }^{13} \mathrm{C}_{6}{ }^{15} \mathrm{~N}_{4}$-Arg or ${ }^{13} \mathrm{C}_{6}{ }^{15} \mathrm{~N}_{2}$-Lys on the C-terminus of the peptide, were synthesized as above. These peptides were then individually validated for synthetic purity, detectability by mass spectrometry, and chromatographic performance. A total of 334 peptides were validated in this manner and were used for the remainder of the study. Collision energies and accumulation times were adjusted for individual peptides to provide optimal fragmentation (43) and adequate signal-to-noise ratios. High-quality tandem mass spectra were collected for each of these peptides, and a spectral library was produced containing all targets using Skyline (44).

Sample processing. For serum samples, $10 \mu \mathrm{L}$ of raw serum was subjected to $9 \mathrm{M}$ urea, $20 \mathrm{mM}$ dithiothreitol, and $0.5 \mathrm{M}$ iodoacetamide, all in Tris buffer at $\mathrm{pH}$ 8.0. Denaturation and reduction occurred simultaneously at $37^{\circ} \mathrm{C}$ for $30 \mathrm{~min}$, with alkylation occurring thereafter in the dark at room temperature for $30 \mathrm{~min}$. Proteolysis was initiated by the addition of TPCK-treated trypsin $(35 \mu \mathrm{L}$ at $1 \mathrm{mg} / \mathrm{mL}$; Worthington) at a 20:1 substrate:enzyme ratio. After overnight incubation at $37^{\circ} \mathrm{C}$, proteolysis was quenched with $1 \%$ formic acid (FA). The SIS peptide mixture was then spiked into the digested samples, the standard curve samples, and the QC samples and concentrated by solid phase extraction (SPE) (Oasis HLB, 2 mg sorbent; Waters). After SPE, the concentrated eluate was frozen, lyophilized to dryness, and rehydrated in $0.1 \%$ FA (final concentration: $0.5 \mu \mathrm{g} / \mu \mathrm{L}$ digest) for LC-MRM/MS. For CSF samples, protein concentration was measured via Bradford assay, and one aliquot from each sample containing $200 \mu \mathrm{g}$ of protein was prepared. Samples were lyophilized and resuspended in $25 \mathrm{mM}$ ammonium bicarbonate $(\mathrm{ABC})$, and protein concentrations were validated by a second Bradford assay. Proteins were digested with trypsin as described (45). A mix of all SIS peptide standards was added, and the sample was cleaned on C18 desalting columns (MacroSpin, Nest Group, Southborough, MA). After C18 cleanup and drying, samples were resuspended in $60 \mathrm{ul}$ of $0.1 \%$ FA.
Mass spectrometry. For serum samples, $20 \mu \mathrm{L}$ injections were separated with a Zorbax Eclipse Plus RP-UHPLC column $(2.1 \times$ $150 \mathrm{~mm}, 1.8 \mu \mathrm{m}$ particle diameter; Agilent) contained within a 1290 Infinity system (Agilent). Peptide separations were achieved at $0.4 \mathrm{~mL} / \mathrm{min}$ over a $60 \mathrm{~min}$ run, via a multi-step LC gradient (2$80 \%$ mobile phase $\mathrm{B}$; mobile phase compositions: A was $0.1 \% \mathrm{FA}$ in water while $\mathrm{B}$ was $0.1 \% \mathrm{FA}$ in acetonitrile). The column was maintained at $40^{\circ} \mathrm{C}$. A post-gradient equilibration of 4 min was performed after each sample. The LC system was interfaced to a triple quadrupole mass spectrometer (Agilent 6490) via a standard-flow ESI source, operated in the positive ion mode. Peptide-specific LCMS acquisition parameters were employed for optimal peptide ionization/fragmentation and scheduled MRM. Peptide optimizations were empirically optimized previously by direct infusion of the purified SIS peptides. Targets (one transition per peptide) were monitored over $500 \mathrm{~ms}$ cycles and $1 \mathrm{~min}$ detection windows.

For CSF samples, two $30 \mu \mathrm{L}$ injections were performed serially, one with each of two PRM acquisition methods. The two methods had identical ionization, calibration, autosampler, and liquid chromatography conditions. Specifically, peptides were separated over a 70 min run, using LC gradients as above; the separation column was a $2.1 \times 250 \mathrm{~mm} \mathrm{C18}$ Poroshell column (Agilent), held at $45^{\circ}$; the flow rate was $100 \mu \mathrm{L} / \mathrm{min}$; and the ion source was the Agilent Jetstream ion source with reference mass calibration. The two methods differed in the peptide targets analyzed, with targets separated into the different methods based on retention time so as to minimize the number of concurrent eluting peptides analyzed per minute. Analysis of the CSF samples was performed on an Agilent 6550 QTOF mass spectrometer, coupled to an Agilent 1260 capillary flow HPLC, and an Agilent 1260 Autosampler.

Data processing and quality control. Data from both serum and CSF samples was visualized and examined using Skyline (44). This involved peak inspection to ensure accurate selection, integration, and uniformity (in terms of peak shape and retention time) of the SIS and natural peptide forms. In the serum, a standard curve was prepared using a mix of light peptides that was spiked into a human tryptic digest in which the peptides were dimethylated (to shift their masses) from a high concentration of $1000 \times$ the lower limit of quantitation (LLOQ) over 8 dilutions to the lowest point of the curve which was the LLOQ for the assay. The QC samples were prepared from the same light peptide mix and diluted in dimethylated human digest at $4 \times, 50 \times$, and $500 \times$ the LLOQ for each peptide. After defining a small number of criteria (i.e., 1/x regression weighting, $<20 \%$ deviation in the QC level accuracy) the standard curve was used to calculate the peptide concentration in $\mathrm{fmol} / \mu \mathrm{l}$ in the patient samples through linear regression. Protein quantitations below or above the LOQ were removed. In the CSF, peak ratios were calculated and extracted using the top six interference-free fragment ions that matched the library spectra. Protein quantitations were removed when the dot product to the library spectrum was less than 0.7 or the maximum peak height was below 20 .

Modularity analysis. Modularity analysis was performed essentially as previously described (18), using the R package 'igraph' (46). Given a network and a grouping of nodes, modularity measures the degree to which nodes within each group are preferentially connected to one another. A weighted network was constructed in which nodes represent samples, and an edge was drawn between pairs of nodes when the Pearson correlation coefficient, computed across all proteins quantified in both samples, was higher than a given threshold. The modularity was subsequently computed with respect to several potential groupings of nodes (including patient, level of injury [cervical, thoracic, or lumbar], injury severity [base- 
line AIS grade], sex, or time post-injury) as a function of network density, defined as the proportion of possible edges used to construct the network.

Univariate analyses. Univariate analysis of protein abundance was performed using linear models with empirical Bayes shrinkage as implemented in the R package 'limma' (47), and p-values were adjusted using Benjamini-Hochberg correction to control the false discovery rate. The plate on which each sample was stored and processed was included in all models in order to guard against the possibility of batch effects. No imputation of missing values was performed for univariate analysis.

In the human dataset, associations between protein abundance and three clinical variables were evaluated: (i) injury status (i.e., comparing samples from patients with acute SCI to uninjured controls); (ii) the severity of the initial injury, assessed using the AIS scale; (iii) recovery of motor function at six months post-injury, quantified by the change in ASIA total motor score ( $\Delta$ TMS); and (iv) improvement in AIS grade at six months. Baseline AIS grade was modeled as an ordinal variable, $\triangle \mathrm{TMS}$ as a continuous variable, and AIS grade improvement as a binary variable. Baseline neurological injury level (e.g., C6 vs. T9) was included as a covariate in models of six-month $\triangle \mathrm{TMS}$ and AIS grade improvement, in order to account for inherently different absolute potentials for motor recovery.

In the pig dataset, associations between protein abundance and four experimental variables were evaluated: (i) injury status (i.e., comparing samples drawn from pigs after experimental SCI to matched samples from the same pigs at baseline); (ii) baseline injury severity, quantified by the height of the weight-drop contusion/compression impactor; (iii) hindlimb neurological recovery, quantified using the average Porcine Thoracic Injury Behavior Scale (PTIBS) score across weeks 10-12 post-injury; and (iv) white matter tissue sparing, quantified by histology at 12 weeks post-injury. Baseline injury severity was modeled as an ordinal variable, whereas hindlimb neurological recovery and white matter tissue sparing were modeled as continuous variables.

Consensus clustering. $\quad k$-means consensus clustering (20) was performed on the matrix of protein $\log _{2}$-fold change values over the first five days post-injury, using the $\mathrm{R}$ package 'ConsensusClusterPlus' (48). The Euclidean distance was used as the distance function, and 100 subsamples were performed. The change in the area under the cumulative distribution function (AUCDF) was used to identify the optimal number of clusters, as the value of $k$ at which there was no appreciable increase in the AUCDF. This procedure yielded a total of nine clusters in the CSF and eight in the serum. Of these, two in the CSF and one in the serum comprised two or fewer proteins and were removed, resulting in seven clusters of temporally co-regulated proteins in each biofluid. Gene Ontology terms enriched within each cluster, relative to the remaining clusters, were identified using the conditional hypergeometric test (49) implemented in the R package 'GOstats' (50).

Multivariate analysis. We implemented an extensive pipeline to develop multivariate diagnostic and prognostic models using the python package 'scikit-learn' (51), encompassing both parametric (e.g., penalized logistic regression) and non-parametric (e.g., gradient boosting machine) approaches. Specifically, for binary or multi-class classification tasks (including baseline AIS grade, baseline AIS A, change in TMS of seven or more points, AIS grade improvement, and motor complete injury at six months), we evaluated twelve different families of models, including Gaussian naive Bayes, $k$-nearest neighbors, nearest-centroid, support vector ma- chine, logistic regression, linear discriminant analysis, random forest, extra trees, adaptive boosting, gradient boosting, and XGBoost classifiers. For the lone regression task, change in TMS at six months, we evaluated a further eleven families of models, including $k$-nearest neighbor, support vector machine, penalized logistic regression (with L1, L2, or elastic net penalties), L1-penalized least angle regression, random forest, extra trees, adaptive boosting, gradient boosting, and XGBoost regressors. Model performance was evaluated in five-fold cross-validation, using the accuracy and balanced accuracy to evaluate multi-class prediction, the AUC and accuracy to evaluate binary prediction, and the coefficient of determination $\left(\mathrm{r}^{2}\right.$ score) to evaluate regression. Hyperparameter grids were adapted from Olson et al. (52), with minor modifications, and are provided in Table S9. In addition to evaluating model hyperparameters, we also evaluated preprocessing choices, including scaling and feature selection, using the scikit-learn 'Pipeline' class. Feature selection was optionally performed by using limma to identify peptides with significant univariate associations to the clinical outcome of interest at nominal significance (that is, uncorrected $p<$ 0.05 ), and was pre-calculated for each cross-validation fold in order to prevent inadvertent leakage of information between training and test splits. We additionally evaluated the impact of providing clinical data from the baseline neurological examination in conjunction with proteomic data, including age, sex, neurological level of injury, baseline AIS grade, baseline UEMS, baseline LEMS, and baseline AMS. Categorical features from the baseline neurological examination (baseline AIS grade and level of injury) were converted to binary indicator variables.

For the analysis of the validation cohort, the best models as determined by cross-validation in the discovery cohort were re-trained on the entirety of the discovery cohort, and projected into the validation cohort to predict clinical outcomes. A total of six models were selected and pre-registered for validation on the basis of the discovery cohort analysis. Samples from the validation cohort were blinded to investigators until the finalization of all statistical analyses of the discovery cohort, in order to provide an independent, blinded validation set.

Cross-species analysis. Unless otherwise noted, all crossspecies analyses were performed on a combined matrix of human and pig protein abundance including all proteins quantified in at least one-third of samples from either species, which was normalized by peptide as described (53). Modularity analysis was performed as described above, after restricting samples to those collected at four timepoints overlapping between species $(24 \mathrm{~h}, 48 \mathrm{~h}$, $72 \mathrm{~h}$, and $120 \mathrm{~h}$ ). The proportion of true null hypotheses, $\pi_{0}$, was estimated using the $\mathrm{R}$ package 'qvalue' (25), from which the estimated proportion of true associations, $\pi_{1}$, was calculated as $1-\pi_{0}$.

Rank-rank hypergeometric overlap analysis 30 was performed using the R package 'RRHO'. Briefly, after performing independent univariate analyses in either species as described above, all proteins quantified in either species were ranked by the strength and direction of DE, and a pair of sliding windows were passed along each of the two ranked lists. The hypergeometric probability of the observed overlap between proteins in each species was calculated for each pair of ranks. The statistical significance of each overlap was calculated by randomly permuting the status (e.g., SCI vs. control) of each human and pig sample, performing an identical univariate analysis with the permuted data, and comparing the maximum $\log 10 \mathrm{p}$-values achieved in 1,000 permutations to the observed value (54).

Neighborhood analysis of conserved coexpression (NACC) (27) was performed to estimate the overall conservation of protein abun- 
dance patterns in SCI between species, and to identify individual proteins or specific pathways with conserved or divergent patterns of abundance. Briefly, independent protein co-expression networks were constructed in either species, using the Pearson correlation coefficient to quantify similarity. The $k$ nearest neighbors of each protein in turn were identified in the human co-expression network, and the mean correlation coefficient between the human neighbors and the protein of interest were calculated in pig. This procedure was repeated with human and pig inverted, and the average correlation across the two comparisons was retained as a symmetric measure of the degree of conservation of co-expression for each protein. We used a neighborhood size of $k=10$, but found our conclusions robust to the neighborhood size (Fig. S10C). Permutation p-values (54) were calculated for each individual protein by comparing the observed NACC score to a distribution of NACC scores derived from 1,000 random sets of 'neighbors'. An identical permutation test was applied to GO terms annotated to between three and 50 proteins in both species, using the average NACC score of all genes within each GO category as the test statistic as previously described (27).

Dynamic time warping was performed using the $\mathrm{R}$ package 'dtw' (55). Samples from uninjured controls and porcine samples collected at 12 weeks post-injury were removed. Abundance profiles for each protein in either species were smoothed using a local polynomial filter to enhance time resolution (56), after which pairwise Euclidean distances were calculated between human and pig protein abundance at each pair of timepoints, and supplied as the local cost matrix to identify the optimal global alignment.

Data availability. The raw mass spectrometry data have been deposited to the ProteomeXchange Consortium (57) via the MassIVE partner repository with the dataset identifier MSV000085567 (reviewer access token: porcinetohuman). Clinical and technical metadata and processed protein abundance data are provided in Tables $\mathbf{S 1}$ and $\mathbf{S 3}$, respectively.
Acknowledgements. This work was supported by Brain Canada, the Michael Smith Foundation for Health Research, Genome Canada, Genome BC, the Djavad Mowfaghian Center for Brain Health, the Praxis Spinal Cord Institute (formerly the Rick Hansen Institute), and the VGH \& UBC Hospital Foundation. The analysis was enabled in part by the support provided by WestGrid and Compute Canada (to L.J.F.), and through computational resources and services provided by Advanced Research Computing at the University of British Columbia (to B.K.K. and L.J.F.). The authors are grateful for the expertise of the dedicated staff at the UBC Center for Comparative Medicine who helped to manage the health and welfare of the animals. M.A.S. acknowledges support from the Canadian Institutes of Health Research (CIHR), a Vancouver Coastal Health-CIHR-UBC MD/PhD Studentship, and the Wings for Life Spinal Cord Research Foundation. Mass spectrometry infrastructure for L.J.F. and C.B. was supported by Genome BC and Genome Canada (214PRO). B.K.K. is the Canada Research Chair in Spinal Cord Injury and the Dvorak Chair in Spine Trauma.

Competing interests. The authors declare no competing financial interests. 


\section{References}

(1) Singh, A., Tetreault, L., Kalsi-Ryan, S., Nouri, A., and Fehlings, M. G. (2014). Global prevalence and incidence of traumatic spinal cord injury. Clin. Epidemiol. 6, 309-331.

(2) Priebe, M. M., Chiodo, A. E., Scelza, W. M., Kirshblum, S. C., Wuermser, L.-A., and Ho, C. H. (2007). Spinal cord injury medicine. 6. Economic and societal issues in spinal cord injury. Arch. Phys. Med. Rehabil. 88, S84-8.

(3) Krueger, H., Noonan, V. K., Trenaman, L. M., Joshi, P., and Rivers, C. S. (2013). The economic burden of traumatic spinal cord injury in Canada. Chronic Dis. Inj. Canada 33, 113-122.

(4) Ramer, L. M., Ramer, M. S., and Bradbury, E. J. (2014). Restoring function after spinal cord injury: towards clinical translation of experimental strategies. Lancet Neurol. 13, 1241-1256.

(5) Gomes-Osman, J., Cortes, M., Guest, J., and PascualLeone, A. (2016). A systematic review of experimental strategies aimed at improving motor function after acute and chronic spinal cord injury. J. Neurotrauma $33,425-438$.

(6) Ahuja, C. S., Wilson, J. R., Nori, S., Kotter, M. R. N., Druschel, C., Curt, A., and Fehlings, M. G. (2017). Traumatic spinal cord injury. Nat. Rev. Dis. Primers 3, 17018.

(7) Tigchelaar, S., and Kwon, B. K. In Neurological aspects of spinal cord injury, Weidner, N., Rupp, R., and Tansey, K. E., Eds.; Springer International Publishing: 2017, pp 721-740.

(8) Lammertse, D. P. (2013). Clinical trials in spinal cord injury: lessons learned on the path to translation. The 2011 International Spinal Cord Society Sir Ludwig Guttmann Lecture. Spinal Cord 51, 2-9.

(9) Lee, R. S., Noonan, V. K., Batke, J., Ghag, A., Paquette, S. J., Boyd, M. C., Fisher, C. G., Street, J., Dvorak, M. F., and Kwon, B. K. (2012). Feasibility of patient recruitment into clinical trials of experimental treatments for acute spinal cord injury. J. Clin. Neurosci. $19,1338-1343$.

(10) Fawcett, J. W. et al. (2007). Guidelines for the conduct of clinical trials for spinal cord injury as developed by the ICCP panel: spontaneous recovery after spinal cord injury and statistical power needed for therapeutic clinical trials. Spinal Cord 45, 190-205.

(11) Kwon, B. K., Bloom, O., Wanner, I.-B., Curt, A., Schwab, J. M., Fawcett, J., and Wang, K. K. (2019). Neurochemical biomarkers in spinal cord injury. Spinal Cord 57, 819-831.

(12) Institute of Medicine (US) Forum on Neuroscience and Nervous System Disorders, Improving the Utility and Translation of Animal Models for Nervous System Disorders: Workshop Summary; The National Academies Collection: Reports funded by National In- stitutes of Health; National Academies Press: Washington, DC, 2013.

(13) Lee, J. H. T., Jones, C. F., Okon, E. B., Anderson, L., Tigchelaar, S., Kooner, P., Godbey, T., Chua, B., Gray, G., Hildebrandt, R., Cripton, P., Tetzlaff, W., and Kwon, B. K. (2013). A novel porcine model of traumatic thoracic spinal cord injury. J. Neurotrauma 30, 142-159.

(14) Bendixen, E., Danielsen, M., Larsen, K., and Bendixen, C. (2010). Advances in porcine genomics and proteomics-a toolbox for developing the pig as a model organism for molecular biomedical research. Brief. Funct. Genomics 9, 208-219.

(15) Tigchelaar, S., Streijger, F., Sinha, S., Flibotte, S., Manouchehri, N., So, K., Shortt, K., Okon, E., Rizzuto, M. A., Malenica, I., Courtright-Lim, A., Eisen, A., Keuren-Jensen, K. V., Nislow, C., and Kwon, B. K. (2017). Serum micrornas reflect injury severity in a large animal model of thoracic spinal cord injury. Sci. Rep. 7, 1376.

(16) Kuzyk, M. A., Smith, D., Yang, J., Cross, T. J., Jackson, A. M., Hardie, D. B., Anderson, N. L., and Borchers, C. H. (2009). Multiple reaction monitoringbased, multiplexed, absolute quantitation of 45 proteins in human plasma. Mol. Cell. Proteomics 8, 18601877.

(17) Kuzyk, M. A., Parker, C. E., Domanski, D., and Borchers, C. H. (2013). Development of MRM-based assays for the absolute quantitation of plasma proteins. Methods Mol. Biol. 1023, 53-82.

(18) Breschi, A., Djebali, S., Gillis, J., Pervouchine, D. D., Dobin, A., Davis, C. A., Gingeras, T. R., and Guigó, R. (2016). Gene-specific patterns of expression variation across organs and species. Genome Biol. 17, 151.

(19) Squair, J. W., Tigchelaar, S., Moon, K.-M., Liu, J., Tetzlaff, W., Kwon, B. K., Krassioukov, A. V., West, C. R., Foster, L. J., and Skinnider, M. A. (2018). Integrated systems analysis reveals conserved gene networks underlying response to spinal cord injury. eLife 7, e39188.

(20) Monti, S., Tamayo, P., Mesirov, J., and Golub, T. (2003). Consensus clustering: a resampling-based method for class discovery and visualization of gene expression microarray data. Mach. Learn. 52, 91-118.

(21) van Middendorp, J. J., Barbagallo, G., Schuetz, M., and Hosman, A. J. F. (2012). Design and rationale of a Prospective, Observational European Multicenter study on the efficacy of acute surgical decompression after traumatic Spinal Cord Injury: the SCI-POEM study. Spinal Cord 50, 686-694.

(22) van Middendorp, J. J., Hosman, A. J. F., and Doi, S. A. R. (2013). The effects of the timing of spinal surgery after traumatic spinal cord injury: a systematic review and meta-analysis. J. Neurotrauma 30, 17811794. 
(23) Geisler, F. H., Coleman, W. P., Grieco, G., Poonian, D., and Group, S. S. (2001). The Sygen multicenter acute spinal cord injury study. Spine 26, S87-98.

(24) Fehlings, M. G., Vaccaro, A., Wilson, J. R., Singh, A., W Cadotte, D., Harrop, J. S., Aarabi, B., Shaffrey, C., Dvorak, M., Fisher, C., Arnold, P., Massicotte, E. M., Lewis, S., and Rampersaud, R. (2012). Early versus delayed decompression for traumatic cervical spinal cord injury: results of the Surgical Timing in Acute Spinal Cord Injury Study (STASCIS). Plos ONE 7, e32037.

(25) Storey, J. D., and Tibshirani, R. (2003). Statistical significance for genomewide studies. Proc. Natl. Acad. Sci. U. S. A. 100, 9440-9445.

(26) Plaisier, S. B., Taschereau, R., Wong, J. A., and Graeber, T. G. (2010). Rank-rank hypergeometric overlap: identification of statistically significant overlap between gene-expression signatures. Nucleic Acids Res. $38, \mathrm{e} 169$.

(27) Yue, F. et al. (2014). A comparative encyclopedia of DNA elements in the mouse genome. Nature 515, 355-364.

(28) Kwon, B. K., Stammers, A. M. T., Belanger, L. M., Bernardo, A., Chan, D., Bishop, C. M., Slobogean, G. P., Zhang, H., Umedaly, H., Giffin, M., Street, J., Boyd, M. C., Paquette, S. J., Fisher, C. G., and Dvorak, M. F. (2010). Cerebrospinal fluid inflammatory cytokines and biomarkers of injury severity in acute human spinal cord injury. J. Neurotrauma 27, 669682.

(29) Streijger, F. et al. (2017). A targeted proteomics analysis of cerebrospinal fluid after acute human spinal cord injury. J. Neurotrauma 34, 2054-2068.

(30) Sengupta, M. B., Basu, M., Iswarari, S., Mukhopadhyay, K. K., Sardar, K. P., Acharyya, B., Mohanty, P. K., and Mukhopadhyay, D. (2014). CSF proteomics of secondary phase spinal cord injury in human subjects: perturbed molecular pathways post injury. PLoS ONE 9, e110885.

(31) Moghieb, A., Bramlett, H. M., Das, J. H., Yang, Z., Selig, T., Yost, R. A., Wang, M. S., Dietrich, W. D., and Wang, K. K. W. (2016). Differential neuroproteomic and systems biology analysis of spinal cord injury. Mol. Cell. Proteomics 15, 2379-2395.

(32) Hulme, C. H., Brown, S. J., Fuller, H. R., Riddell, J., Osman, A., Chowdhury, J., Kumar, N., Johnson, W. E., and Wright, K. T. (2017). The developing landscape of diagnostic and prognostic biomarkers for spinal cord injury in cerebrospinal fluid and blood. Spinal Cord $55,114-125$.

(33) Seok, J. et al. (2013). Genomic responses in mouse models poorly mimic human inflammatory diseases. Proc. Natl. Acad. Sci. U. S. A. 110, 3507-3512.

(34) Takao, K., and Miyakawa, T. (2015). Genomic responses in mouse models greatly mimic human inflammatory diseases. Proc. Natl. Acad. Sci. U. S. A. 112, 1167-1172.
(35) Normand, R., Du, W., Briller, M., Gaujoux, R., Starosvetsky, E., Ziv-Kenet, A., Shalev-Malul, G., Tibshirani, R. J., and Shen-Orr, S. S. (2018). Found In Translation: a machine learning model for mouseto-human inference. Nat. Methods 15, 1067-1073.

(36) Courtine, G., Bunge, M. B., Fawcett, J. W., Grossman, R. G., Kaas, J. H., Lemon, R., Maier, I., Martin, J., Nudo, R. J., Ramon-Cueto, A., Rouiller, E. M., Schnell, L., Wannier, T., Schwab, M. E., and Edgerton, V. R. (2007). Can experiments in nonhuman primates expedite the translation of treatments for spinal cord injury in humans? Nat. Med. 13, 561-566.

(37) Addona, T. A., Shi, X., Keshishian, H., Mani, D. R., Burgess, M., Gillette, M. A., Clauser, K. R., Shen, D., Lewis, G. D., Farrell, L. A., Fifer, M. A., Sabatine, M. S., Gerszten, R. E., and Carr, S. A. (2011). A pipeline that integrates the discovery and verification of plasma protein biomarkers reveals candidate markers for cardiovascular disease. Nat. Biotechnol. 29, 635-643.

(38) Hüttenhain, R., Soste, M., Selevsek, N., Röst, H., Sethi, A., Carapito, C., Farrah, T., Deutsch, E. W., Kusebauch, U., Moritz, R. L., Niméus-Malmstrm, E., Rinner, O., and Aebersold, R. (2012). Reproducible quantification of cancer-associated proteins in body fluids using targeted proteomics. Sci. Transl. Med. 4, $142 \mathrm{ra} 94$.

(39) Streijger, F., Lee, J. H. T., Chak, J., Dressler, D., Manouchehri, N., Okon, E. B., Anderson, L. M., Melnyk, A. D., Cripton, P. A., and Kwon, B. K. (2015). The effect of whole-body resonance vibration in a porcine model of spinal cord injury. J. Neurotrauma 32, 908-921.

(40) Streijger, F., Lee, J. H. T., Manouchehri, N., Melnyk, A. D., Chak, J., Tigchelaar, S., So, K., Okon, E. B., Jiang, S., Kinsler, R., Barazanji, K., Cripton, P. A., and Kwon, B. K. (2016). Responses of the acutely injured spinal cord to vibration that simulates transport in helicopters or mine-resistant ambush-protected vehicles. J. Neurotrauma 33, 2217-2226.

(41) Clinical Proteomic Tumor Analysis Consortium Assay Characterization Guidance Documents., 2015.

(42) Mohammed, Y., Domanski, D., Jackson, A. M., Smith, D. S., Deelder, A. M., Palmblad, M., and Borchers, C. H. (2014). PeptidePicker: a scientific workflow with web interface for selecting appropriate peptides for targeted proteomics experiments. J. Proteomics 106, $151-161$.

(43) Rogalski, J. C., Lin, M. S., Sniatynski, M. J., Taylor, R. J., Youhnovski, N., Przybylski, M., and Kast, J. (2005). Statistical evaluation of electrospray tandem mass spectra for optimized peptide fragmentation. $J$. Am. Soc. Mass Spectrom. 16, 505-514.

(44) Pino, L. K., Searle, B. C., Bollinger, J. G., Nunn, B., MacLean, B., and MacCoss, M. J. (2020). The Skyline ecosystem: Informatics for quantitative mass spec- 
trometry proteomics. Mass Spectrom. Rev. 39, 229244.

(45) Proc, J. L., Kuzyk, M. A., Hardie, D. B., Yang, J., Smith, D. S., Jackson, A. M., Parker, C. E., and Borchers, C. H. (2010). A quantitative study of the effects of chaotropic agents, surfactants, and solvents on the digestion efficiency of human plasma proteins by trypsin. J. Proteome Res. 9, 5422-5437.

(46) Csardi, G., and Nepusz, T. (2006). The igraph software package for complex network research. InterJournal Complex Systems 1695, 1-9.

(47) Ritchie, M. E., Phipson, B., Wu, D., Hu, Y., Law, C. W., Shi, W., and Smyth, G. K. (2015). limma powers differential expression analyses for RNAsequencing and microarray studies. Nucleic Acids Res. 43, e47.

(48) Wilkerson, M. D., and Hayes, D. N. (2010). ConsensusClusterPlus: a class discovery tool with confidence assessments and item tracking. Bioinformatics 26, 1572-1573.

(49) Alexa, A., Rahnenführer, J., and Lengauer, T. (2006). Improved scoring of functional groups from gene expression data by decorrelating GO graph structure. Bioinformatics 22, 1600-1607.

(50) Falcon, S., and Gentleman, R. (2007). Using GOstats to test gene lists for $\mathrm{GO}$ term association. Bioinformatics 23, 257-258.

(51) Pedregosa, F. et al. (2011). Scikit-learn: machine learning in Python. J. Mach. Learn. Res. 12, 28252830.

(52) Olson, R. S., Cava, W. L., Mustahsan, Z., Varik, A., and Moore, J. H. (2018). Data-driven advice for applying machine learning to bioinformatics problems. Pac. Symp. Biocomput. 23, 192-203.

(53) Zheng-Bradley, X., Rung, J., Parkinson, H., and Brazma, A. (2010). Large scale comparison of global gene expression patterns in human and mouse. Genome Biol. 11, R124.

(54) Phipson, B., and Smyth, G. K. (2010). Permutation Pvalues should never be zero: calculating exact $P$-values when permutations are randomly drawn. Stat. Appl. Genet. Mol. Biol. 9, Article39.

(55) Giorgino, T. (2009). Computing and visualizing dynamic time warping alignments in $\mathrm{R}$ : the $\mathrm{dtw}$ package. J. Stat. Softw. 31, 1-24.

(56) Schafer, S. T., Paquola, A. C. M., Stern, S., Gosselin, D., Ku, M., Pena, M., Kuret, T. J. M., Liyanage, M., Mansour, A. A., Jaeger, B. N., Marchetto, M. C., Glass, C. K., Mertens, J., and Gage, F. H. (2019). Pathological priming causes developmental gene network heterochronicity in autistic subject-derived neurons. Nat. Neurosci. 22, 243-255.

(57) Vizcaíno, J. A. et al. (2014). ProteomeXchange provides globally coordinated proteomics data submission and dissemination. Nat. Biotechnol. 32, 223-226. 
bioRxiv preprint doi: https://doi.org/10.1101/2021.01.27.428528; this version posted January 28, 2021. The copyright holder for this preprint (which was not certified by peer review) is the author/funder, who has granted bioRxiv a license to display the preprint in perpetuity. It is made available under aCC-BY-NC-ND 4.0 International license.

A

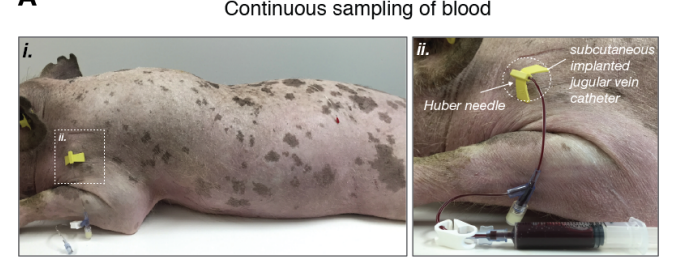

D
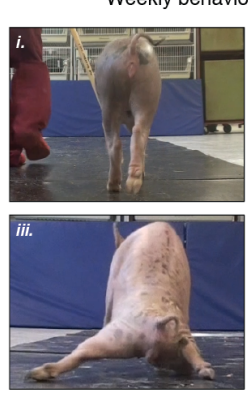

G

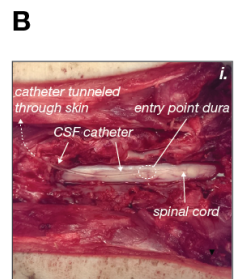

E

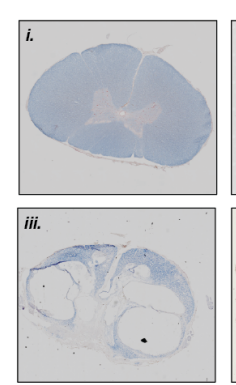

$\rightarrow$ Sham $\rightarrow$ Mild $\rightarrow$ Moderate $\rightarrow$ Severe

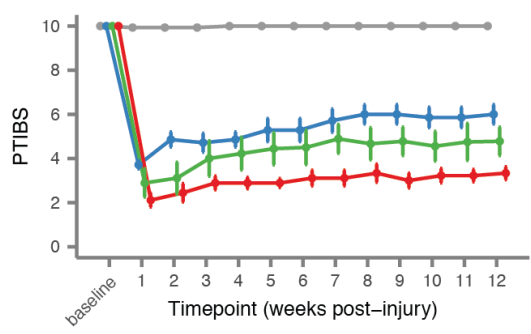

Continuous sampling of cerebrospinal fluid
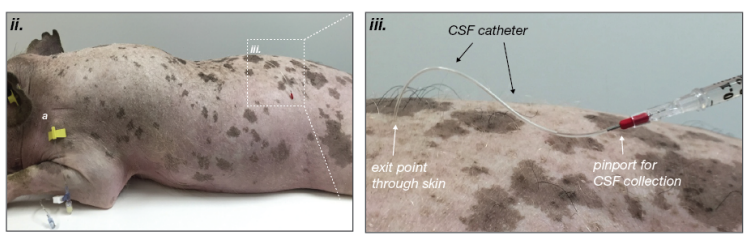

Histological assessment (12 weeks post-injury)

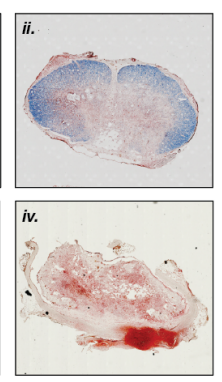

H

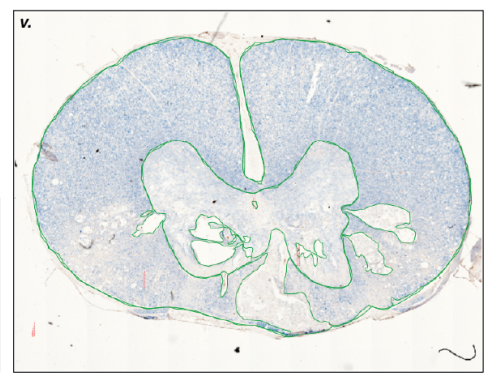

$\leadsto$ Sham $\leadsto$ Mild $\leadsto$ Moderate $\rightarrow$ Severe

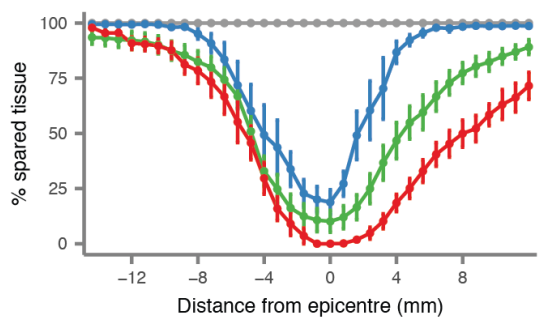

Fig. S1: Experimental study of $\mathrm{SCl}$ in a large animal model, the Yucatan pig.

(A-B) Overview of surgical and experimental setup for continuous collection of CSF (A) and serum (B) samples.

(C-E) Overview of key experimental outcomes.

(C) Baseline injury severity was quantified by impactor height (mild, $10 \mathrm{~cm}$; moderate, $20 \mathrm{~cm}$; severe, $40 \mathrm{~cm}$ ).

(D) Neurological recovery was quantified by weekly behavioral assessments using the Porcine Thoracic Injury Behavioral Scale (PTIBS) for hindlimb function. Representative images from PTIBS assessments are shown for sham (i), mild (ii), moderate (iii), and severe (iv) injuries.

(E) Tissue sparing was quantified by histology at 12 weeks post-injury, on the basis of cross-sections of the spinal cord from $13.6 \mathrm{~mm}$ rostral to $13.6 \mathrm{~mm}$ caudal to the lesion site, in increments of $0.8 \mathrm{~mm}$. Slides were manually traced to determine the extent of spared tissue $(v)$.

(F) Maximum force delivered, in kDyn, to animals in each of four treatment groups.

(G) Mean PTIBS scores for animals in each of four treatment groups over the first twelve weeks post-injury. Bars show standard error.

$(\mathrm{H})$ Mean proportion of spared tissue in sections taken from $13.6 \mathrm{~mm}$ rostral to $13.6 \mathrm{~mm}$ caudal to the lesion, relative to the entire area of the spinal cord on histological section. Bars show standard error. 
bioRxiv preprint doi: https://doi.org/10.1101/2021.01.27.428528; this version posted January 28, 2021. The copyright holder for this preprint (which was not certified by peer review) is the author/funder, who has granted bioRxiv a license to display the preprint in perpetuity. It is made available under aCC-BY-NC-ND 4.0 International license.

A
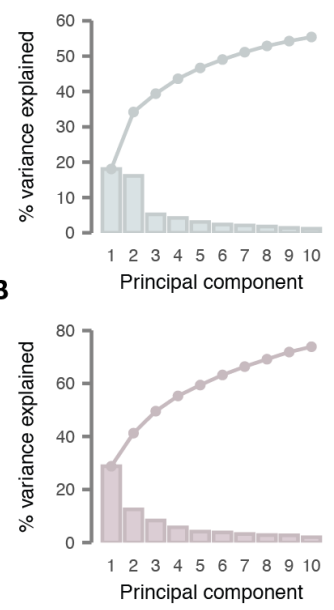

C
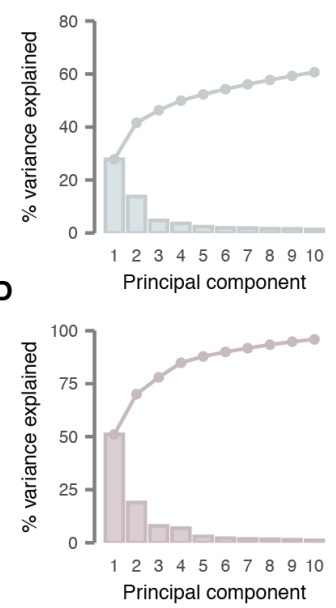

Time post-injury

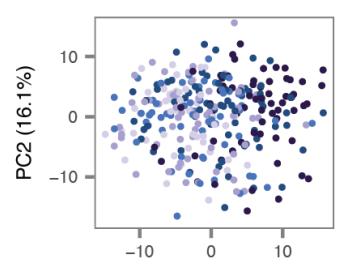

PC1 (18.1\%)

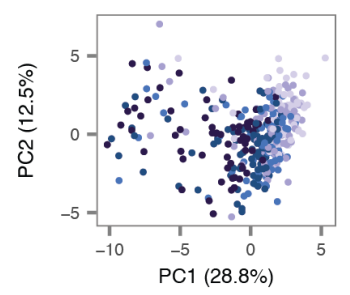

Time post-injury $12 \mathrm{~h}: 48 \mathrm{~h}: 120 \mathrm{~h}$
$-24 \mathrm{~h}: 72 \mathrm{~h}: 12 \mathrm{w}$
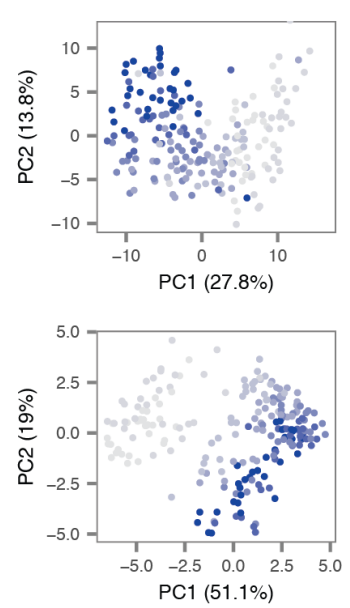

Baseline AIS - $A \bullet B \bullet C$

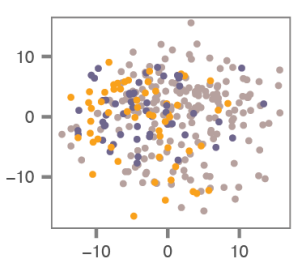

PC1 (18.1\%)

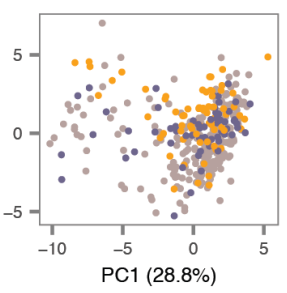

Treatment group

Mild
Moderate Sham
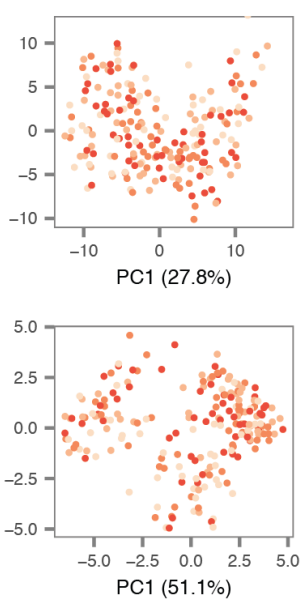

Level of injury

- Cervical - Thoracic • Lumbar

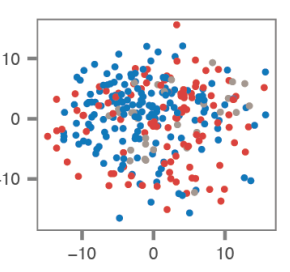

PC1 (18.1\%)

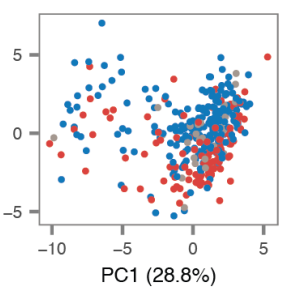

PTIBS $\begin{array}{llll}4 & 6 & 8 & 10\end{array}$
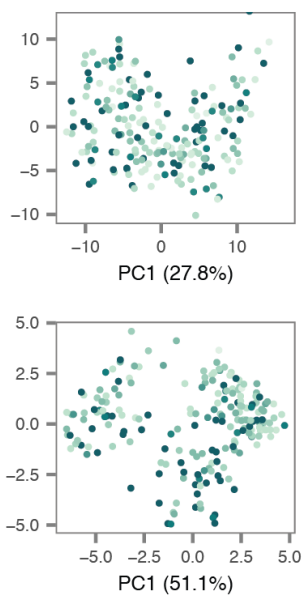

Conversion

Did not convert $\bullet$ Converted

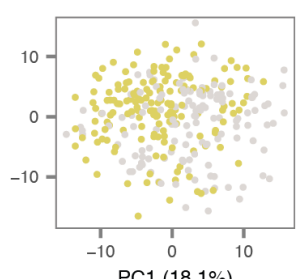

PC1 (18.1\%)

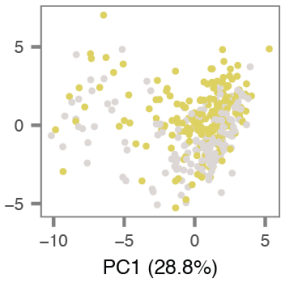

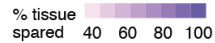
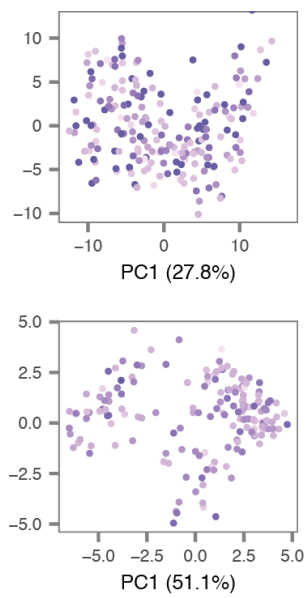

Fig. S2: Principal component analysis of CSF and serum proteomes in human and pig.

(A) Principal component analysis of CSF proteomics data from the human cohort. Left, percent of variance explained by principal components 1 to 10 (bars) or cumulatively by the first 1 to 10 principal components (line). Right, biplot of the first two principal components (PC1 and PC2) with samples coloured by time post-injury, baseline AIS grade, level of injury, or AIS conversion.

(B) As in (A), but for the serum proteomics data from the human cohort.

(C) Principal component analysis of CSF proteomics data from the pig cohort. Left, percent of variance explained by principal components 1 to 10 (bars) or cumulatively by the first 1 to 10 principal components (line). Right, biplot of the first two principal components (PC1 and PC2) with samples coloured by time post-injury, treatment group (baseline injury severity), PTIBS score at 12 weeks postinjury, and percentage of tissue spared as assessed by histology at 12 weeks post-injury.

(D) As in (C), but for the serum proteomics data from the pig cohort. 
bioRxiv preprint doi: https://doi.org/10.1101/2021.01.27.428528; this version posted January 28, 2021. The copyright holder for this preprint (which was not certified by peer review) is the author/funder, who has granted bioRxiv a license to display the preprint in perpetuity. It is made available under aCC-BY-NC-ND 4.0 International license.

A
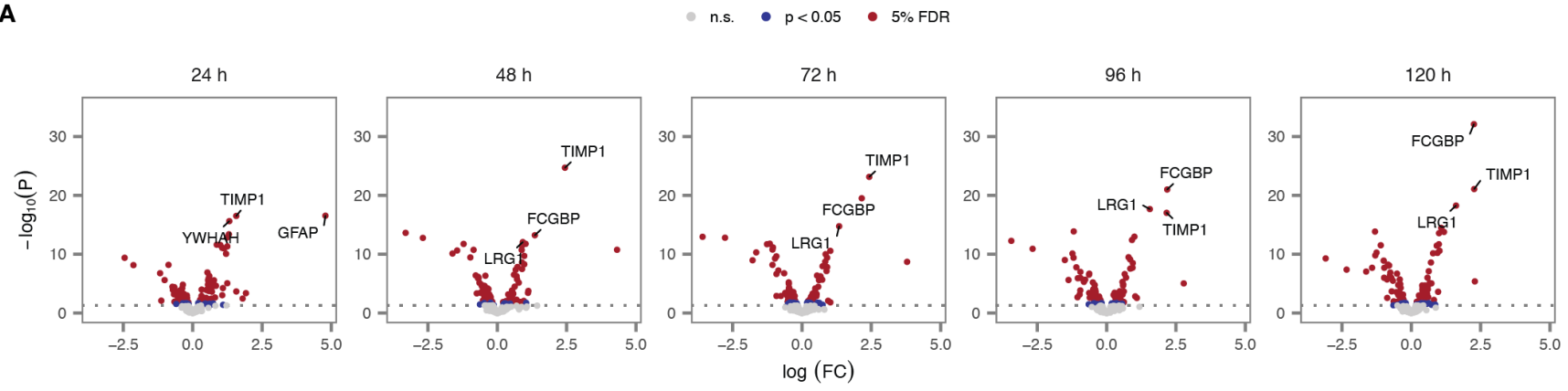

B

$$
\log _{2}(\mathrm{FC}) \quad-1 \quad 0 \quad 1 \quad>2
$$
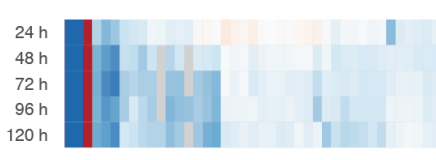

C
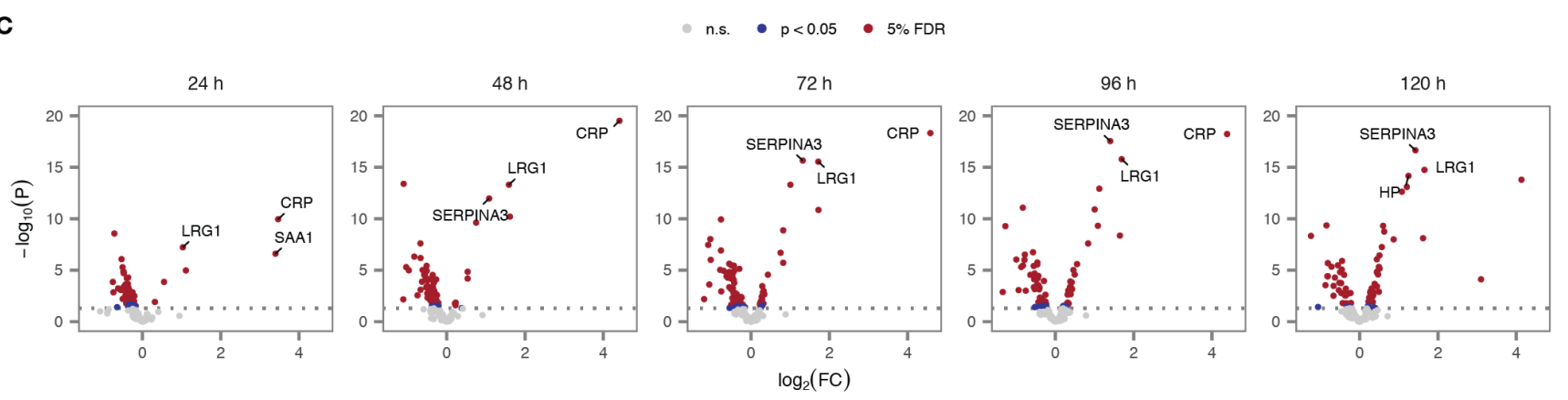

D

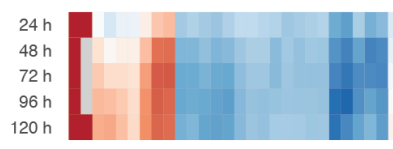

$\log _{2}(\mathrm{FC}) \begin{array}{llll}-1 & 0 & 1 & >2\end{array}$

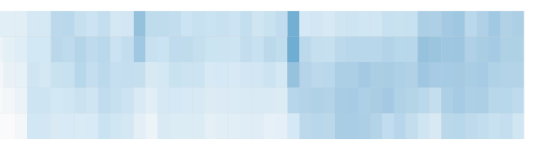

E

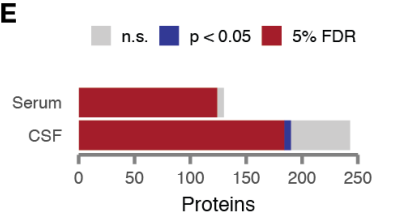

Fig. S3: Alterations in CSF and serum protein abundance in acute SCl.

(A) Volcano plots of differential protein abundance between $24 \mathrm{~h}$ and $120 \mathrm{~h}$ post-injury in CSF samples from patients with acute SCI compared to uninjured controls.

(B) Time courses of differential protein abundance (log-fold change, relative to uninjured controls) over the first five days post-injury for $171 \mathrm{CSF}$ proteins differentially expressed between SCl and control samples within at least one timepoint.

(C) As in (A), but showing differential abundance of serum proteins compared to uninjured controls.

(D) As in (B), but showing time courses of 92 serum proteins differentially expressed between $\mathrm{SCl}$ and control samples within at least one timepoint.

(E) Numbers of CSF and serum proteins that display a statistically significant association with time post-injury. 
bioRxiv preprint doi: https://doi.org/10.1101/2021.01.27.428528; this version posted January 28, 2021. The copyright holder for this preprint (which was not certified by peer review) is the author/funder, who has granted bioRxiv a license to display the preprint in perpetuity. It is made available under aCC-BY-NC-ND 4.0 International license.

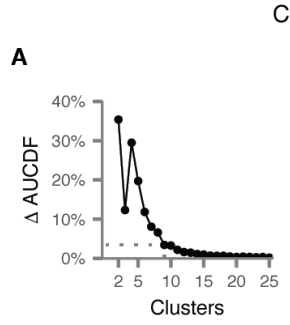

CSF
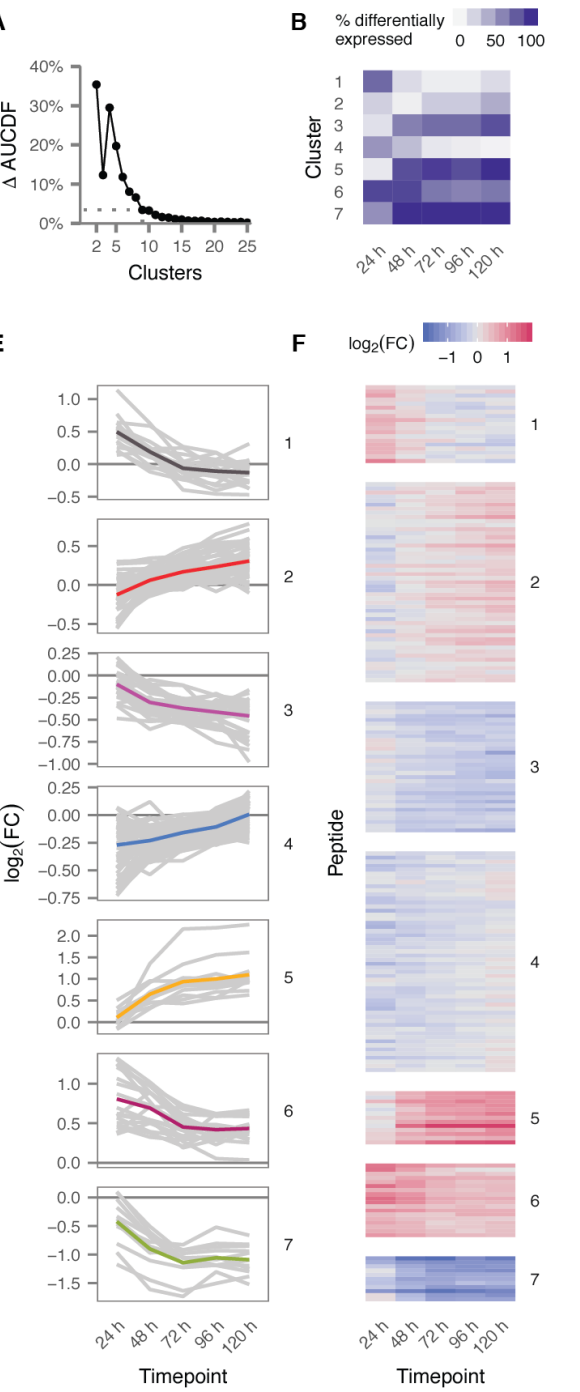

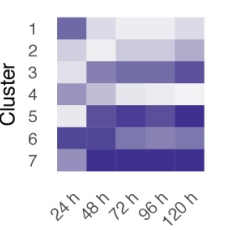

F $\quad \log _{2}(\mathrm{FC})$
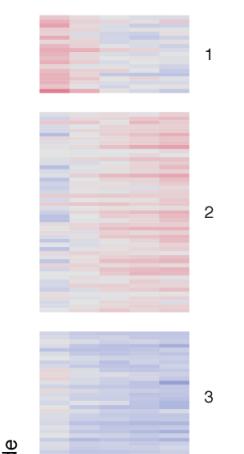

$\frac{0}{\frac{0}{0}}$
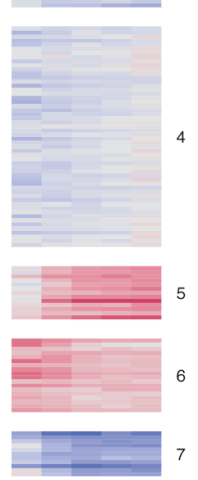

$2^{n n} x^{n} 1^{n} 2^{n} 0^{n}+2^{n}$

Timepoint
C

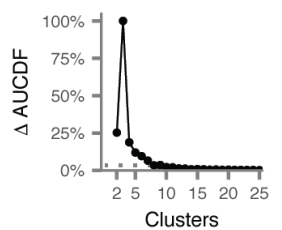

G
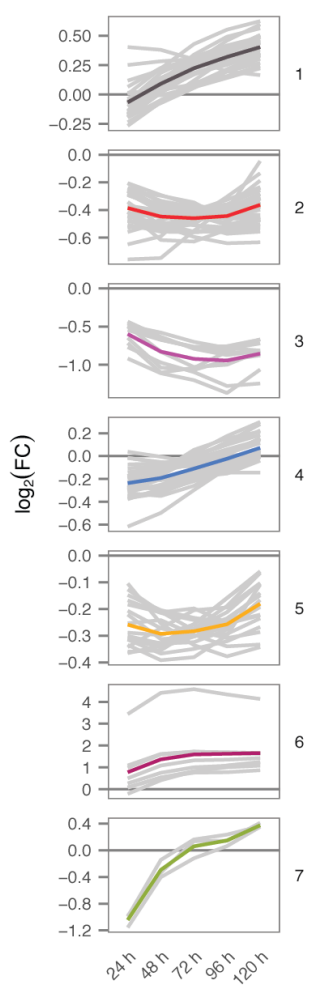

Timepoint
Serum

$\begin{array}{llll}\text { D } \begin{array}{l}\% \text { differentially } \\ \text { expressed }\end{array} & 0 & 50 & 100\end{array}$

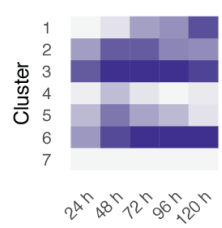

H $\quad \log _{2}(\mathrm{FC}) \mathbb{- 1}_{-1} \quad 0 \quad 1$

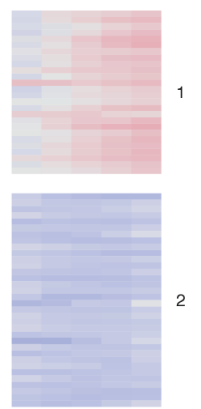

$\frac{\frac{0}{0}}{\frac{0}{20}}$
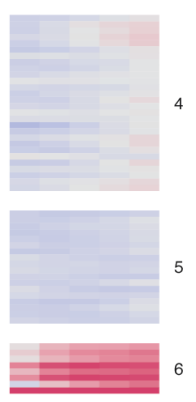

$2^{n} \times x^{n} 1^{n} 2^{n} 6^{n}, 2^{n}$

Timepoint

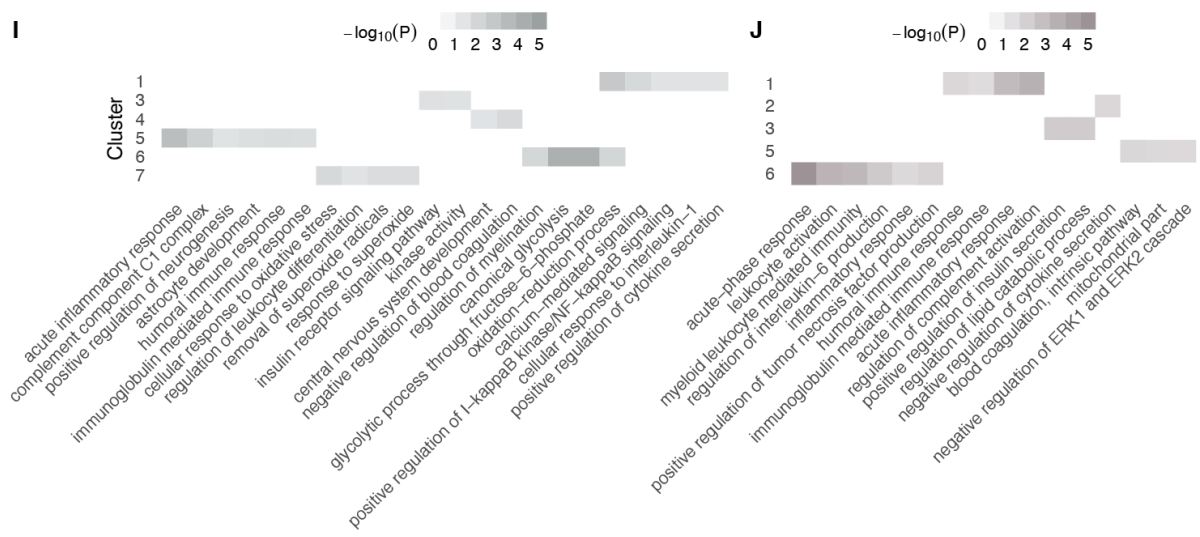


bioRxiv preprint doi: https://doi.org/10.1101/2021.01.27.428528; this version posted January 28, 2021. The copyright holder for this preprint (which was not certified by peer review) is the author/funder, who has granted bioRxiv a license to display the preprint in perpetuity. It is made available under aCC-BY-NC-ND 4.0 International license.

Fig. S4: Modules of temporally co-regulated CSF and serum proteins in acute SCI.

(A) Relative change in the area under the cumulative distribution function (20) comparing consensus clustering solutions of $k$ and $k-$ 1 clusters of the CSF proteome. The optimal number of clusters was determined for each tissue as the value of $k$ at which there was no appreciable increase in the AUCDF.

(B) Proportion of peptides from each cluster found to be differentially expressed between acute SCI patients and uninjured controls at each timepoint.

(C-D) As in (A-B), but for the serum proteome. (E) Time courses of differential protein abundance (log-fold change, relative to uninjured controls) over the first five days post-injury for peptides in each of the seven CSF protein modules, grey lines, and the mean time course for the entire module, colored line.

(F) Time courses of differential protein abundance, as in c, shown as a heatmap.

$(\mathrm{G}-\mathrm{H})$ As in $(\mathrm{E}-\mathrm{F})$, but for the serum proteome.

(I-J) GO terms enriched in each of each of the seven CSF (I) and serum (J) protein modules. 
bioRxiv preprint doi: https://doi.org/10.1101/2021.01.27.428528; this version posted January 28, 2021. The copyright holder for this preprint (which was not certified by peer review) is the author/funder, who has granted bioRxiv a license to display the preprint in perpetuity. It is made available under aCC-BY-NC-ND 4.0 International license.
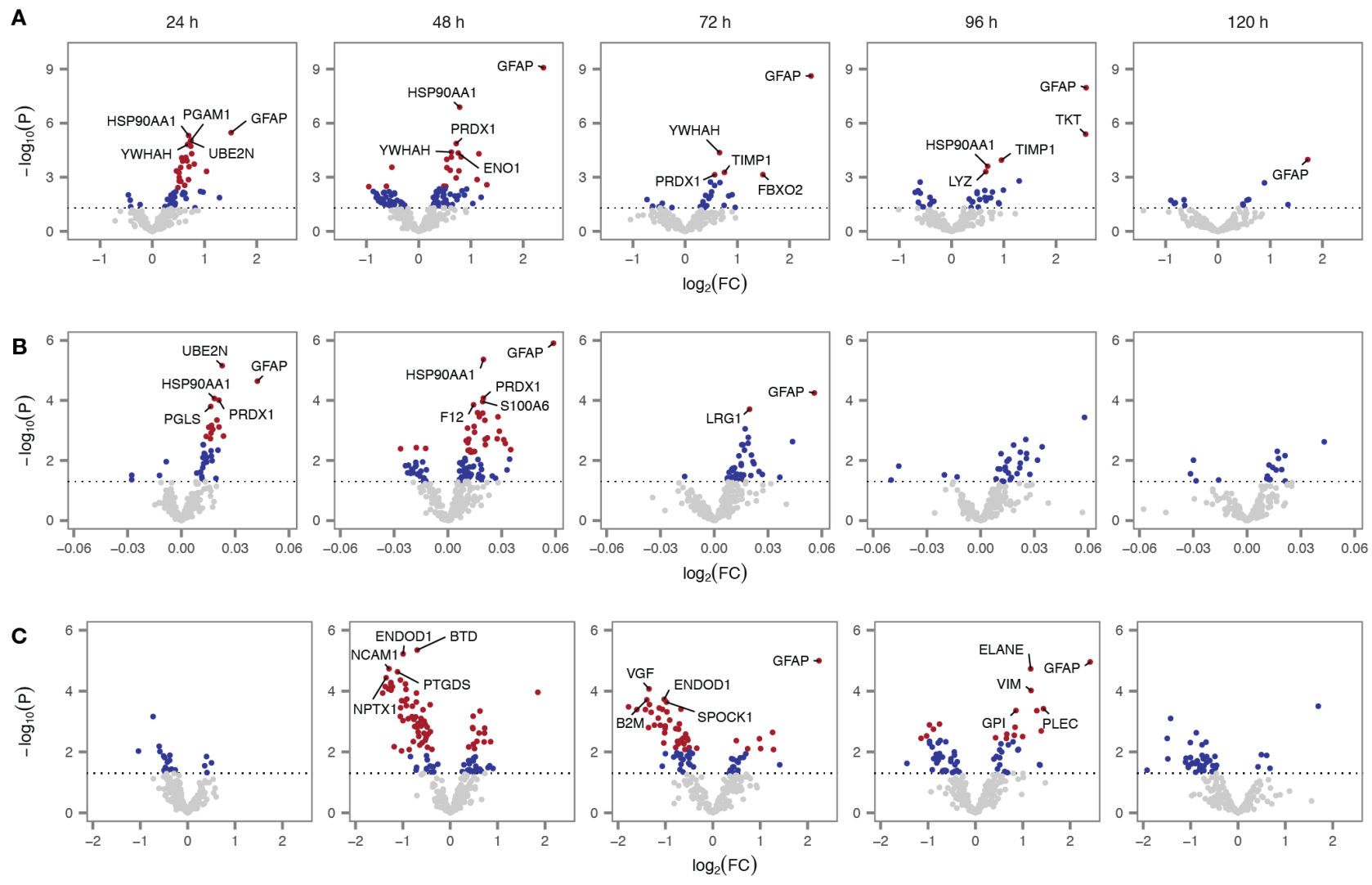

D
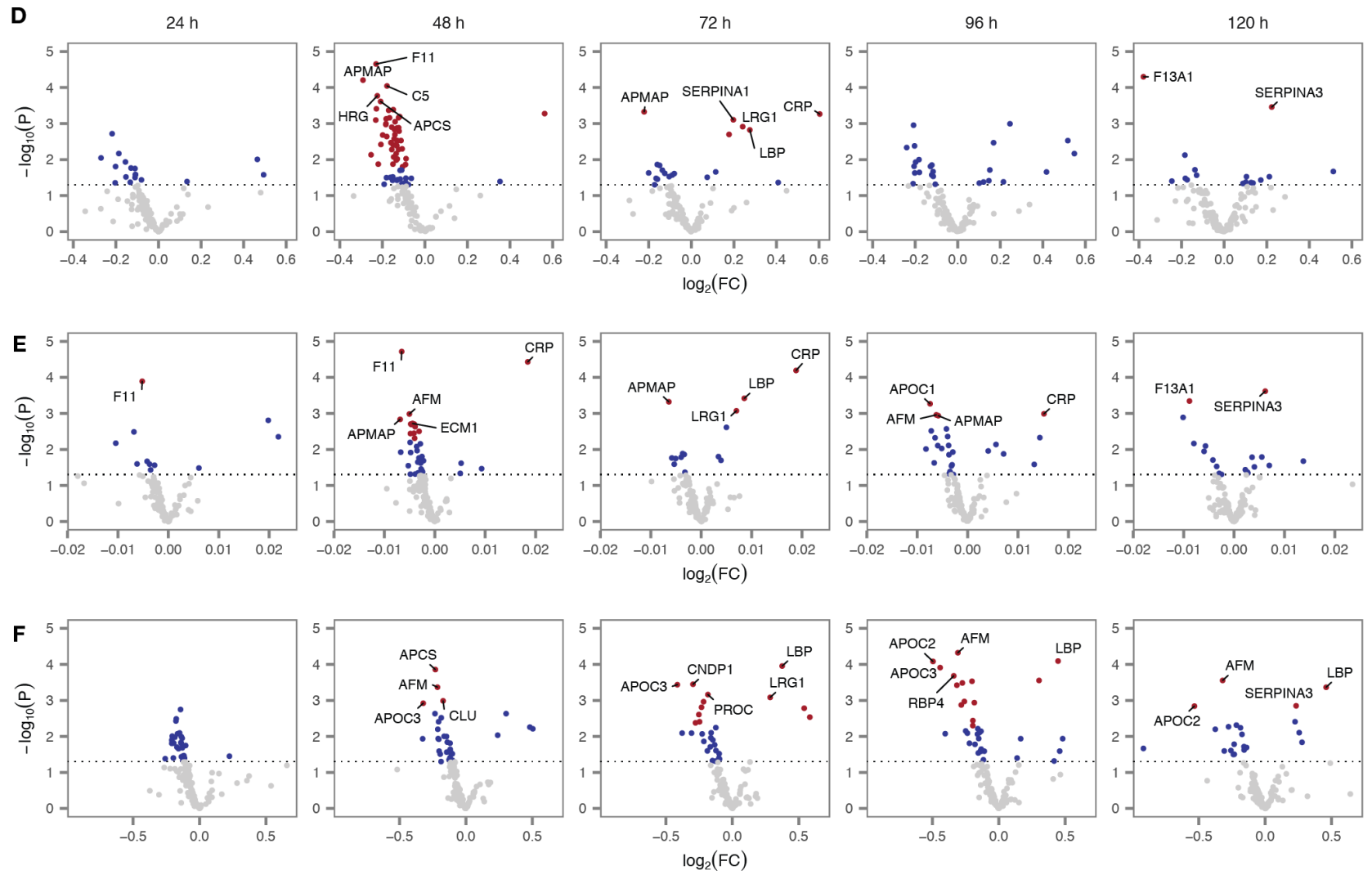
bioRxiv preprint doi: https://doi.org/10.1101/2021.01.27.428528; this version posted January 28, 2021. The copyright holder for this preprint (which was not certified by peer review) is the author/funder, who has granted bioRxiv a license to display the preprint in perpetuity. It is made available under aCC-BY-NC-ND 4.0 International license.

Fig. S5: Univariate analysis of injury severity and neurological recovery in human serum and CSF.

(A) Volcano plots of differential protein abundance as a function of injury severity, as quantified by the baseline AIS grade, in CSF samples between $24 \mathrm{~h}$ and $120 \mathrm{~h}$ post-injury.

(B) Volcano plots of differential protein abundance as a function of neurological recovery at six months post-injury, as quantified by the change in total motor score relative to baseline, in CSF samples between $24 \mathrm{~h}$ and $120 \mathrm{~h}$ post-injury.

(C) Volcano plots of differential protein abundance as a function of neurological recovery at six months post-injury, as quantified by improvement in the AIS grade relative to baseline, in CSF samples between $24 \mathrm{~h}$ and $120 \mathrm{~h}$ post-injury.

(D) As in (A), but for serum samples.

(E) As in (B), but for serum samples.

(F) As in (C), but for serum samples. 
bioRxiv preprint doi: https://doi.org/10.1101/2021.01.27.428528; this version posted January 28, 2021. The copyright holder for this preprint (which was not certified by peer review) is the author/funder, who has granted bioRxiv a license to display the preprint in perpetuity. It is made available under aCC-BY-NC-ND 4.0 International license.
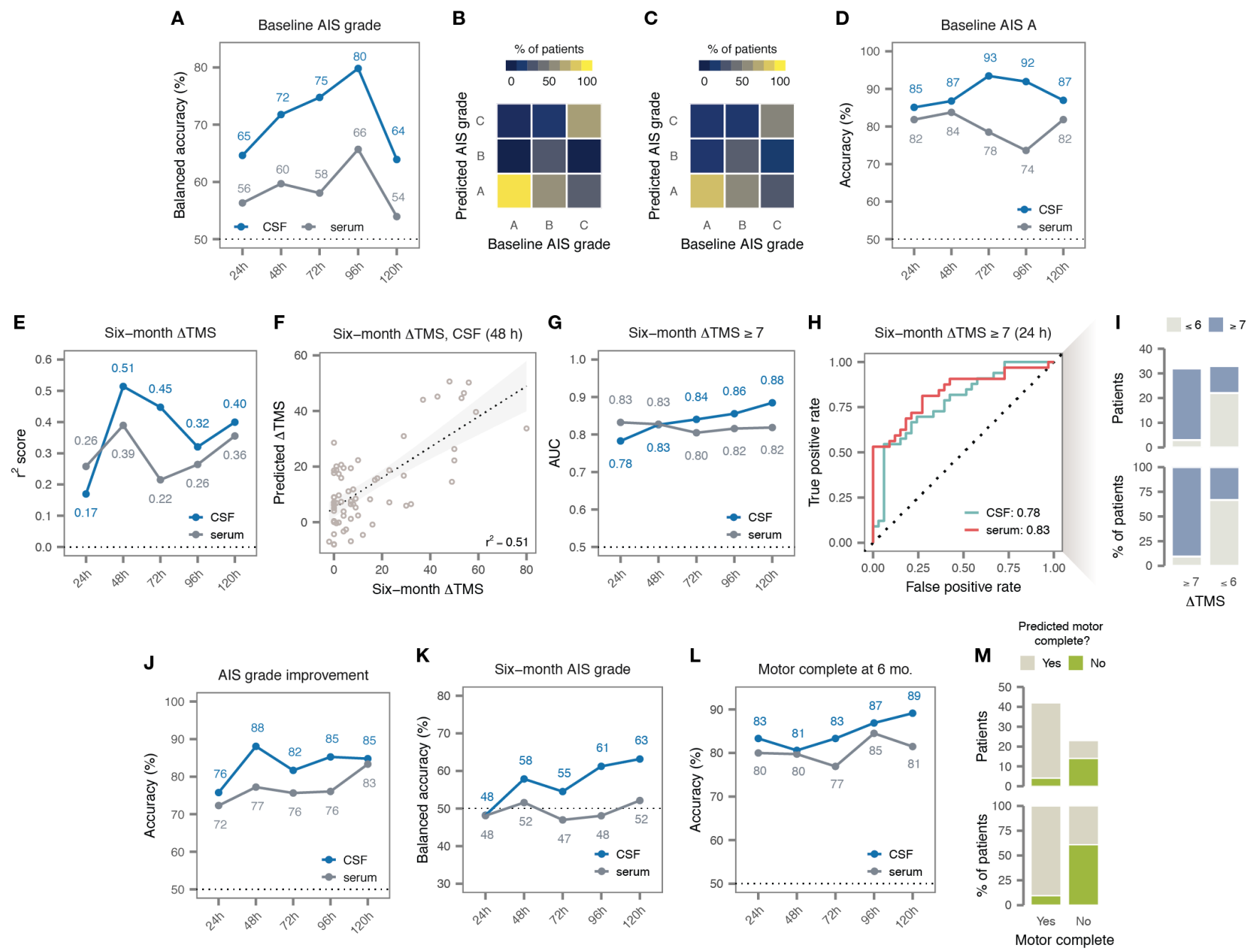

Fig. S6: Additional multivariate analysis of $\mathrm{SCl}$ severity and recovery.

(A) Cross-validation balanced accuracy of multivariate diagnostic models trained to stratify patients by baseline AIS grade, at timepoints between 24 and $120 \mathrm{~h}$ post-injury.

(B) Confusion matrix of the best CSF diagnostic model of baseline AIS grade at $24 \mathrm{~h}$ post-injury.

(C) Confusion matrix of the best serum diagnostic model of baseline AIS grade at $24 \mathrm{~h}$ post-injury.

(D) Cross-validation accuracy of multivariate diagnostic models trained to discern patients with a baseline AIS grade of A, at timepoints between 24 and $120 \mathrm{~h}$ post-injury.

(E) Cross-validation coefficient of determination $\left(r^{2}\right.$ score) of multivariate prognostic models trained to predict the change in TMS at six months post-injury, relative to baseline, at timepoints between 24 and $120 \mathrm{~h}$ post-injury.

(F) Predictions made by the best CSF prognostic model of six-month change in TMS at $48 \mathrm{~h}$ post-injury.

(G) Cross-validation AUC of multivariate prognostic models trained to predict a change in TMS of seven or more points at six months post-injury, at timepoints between 24 and $120 \mathrm{~h}$ post-injury.

(H) ROC curves of the best CSF and serum prognostic models of six-month change in TMS of seven or more points at $24 \mathrm{~h}$ post-injury.

(I) Predictions made by the best serum prognostic model at $24 \mathrm{~h}$ post-injury.

(J) Cross-validation accuracy of multivariate prognostic models trained to predict improvement in AIS grade at six months post-injury, relative to baseline, at timepoints between 24 and $120 \mathrm{~h}$ post-injury.

(K) Cross-validation balanced accuracy of multivariate prognostic models trained to predict AIS grade at six months, at timepoints between 24 and $120 \mathrm{~h}$ post-injury.

(L) Cross-validation accuracy of multivariate prognostic models trained to predict motor complete vs. incomplete injury at six months, at timepoints between 24 and $120 \mathrm{~h}$ post-injury.

(M) Predictions made by the best serum prognostic model of motor complete vs. incomplete injury at six months, at $24 \mathrm{~h}$ post-injury. 
bioRxiv preprint doi: https://doi.org/10.1101/2021.01.27.428528; this version posted January 28, 2021. The copyright holder for this preprint (which was not certified by peer review) is the author/funder, who has granted bioRxiv a license to display the preprint in perpetuity. It is made available under aCC-BY-NC-ND 4.0 International license.

A
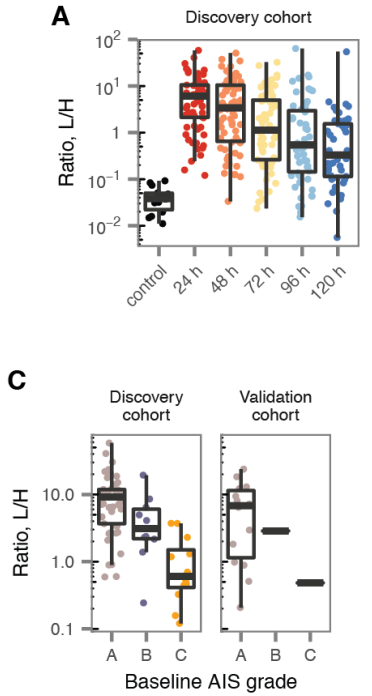
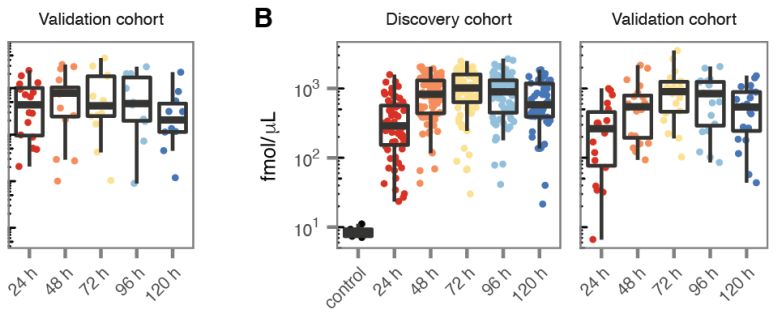

D

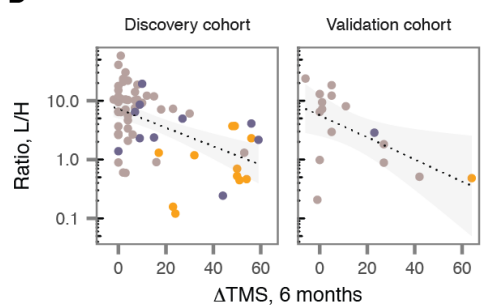

E

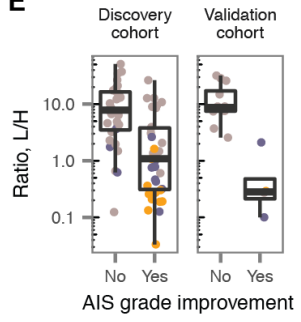

$\mathbf{F}$

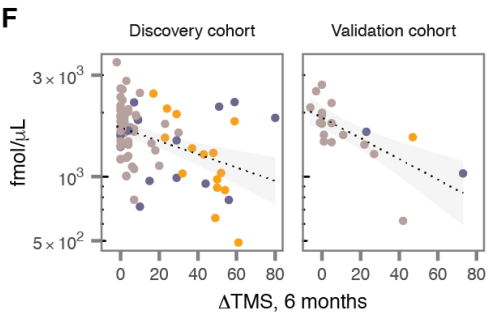

H

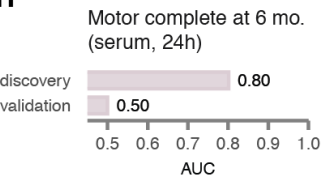

I

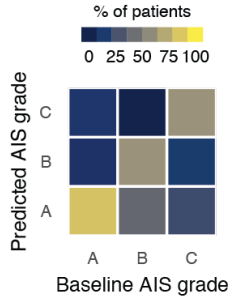

J

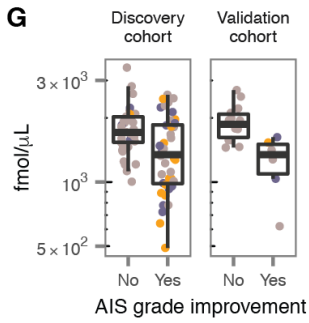

K
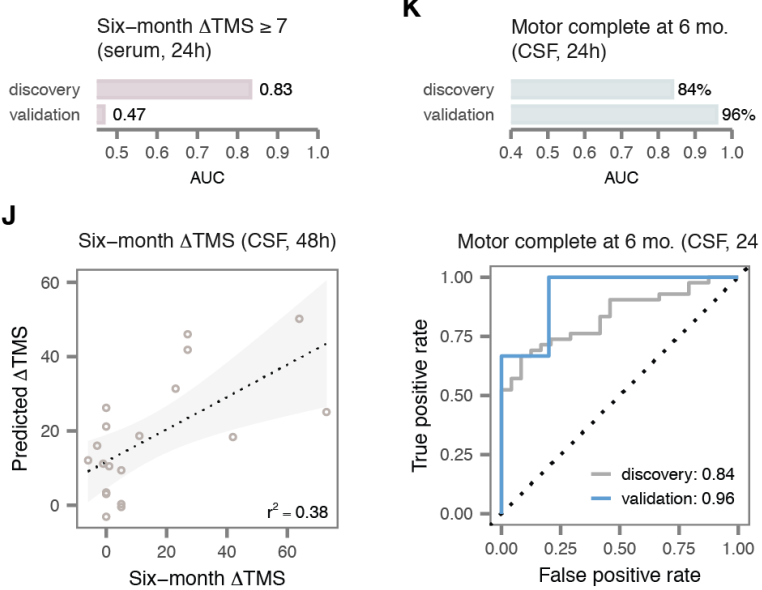

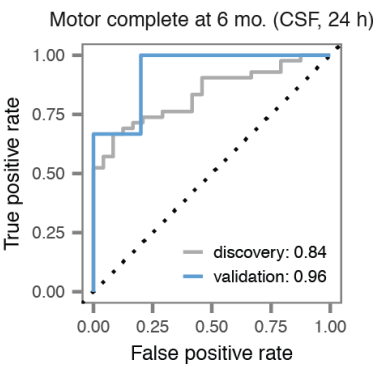

Fig. S7: Replication of univariate associations and multivariate models in an independent validation cohort.

(A) Time course of CSF abundance for an exemplary protein with replicated alterations between acute SCI patients and uninjured controls, GFAP.

(B) Time course of serum abundance for an exemplary protein with replicated alterations between acute $\mathrm{SCl}$ patients and uninjured controls, CRP.

(C-G) Examples of proteins with univariate associations to severity or recovery replicated in the validation cohort.

(C) Abundance of GFAP in CSF samples at $24 \mathrm{~h}$, stratified by baseline AIS grade.

(D) Abundance of GFAP in CSF samples at $24 \mathrm{~h}$, stratified by change in TMS at six months post-injury.

(E) Abundance of GFAP in CSF samples at $48 \mathrm{~h}$, stratified by improvement in AIS grade at six months post-injury.

(F) Abundance of LRG1 in serum samples at $72 \mathrm{~h}$, stratified by change in TMS at six months post-injury.

(G) Abundance of LRG1 in serum samples at $72 \mathrm{~h}$, stratified by improvement in AIS grade at six months post-injury.

(H) Performance of two preregistered serum multivariate models in the validation cohort.

(I) Confusion matrix of the best CSF diagnostic model of baseline AIS grade at $48 \mathrm{~h}$ post-injury in the validation cohort.

(J) Performance of the best CSF prognostic model of six-month change in TMS at $48 \mathrm{~h}$ post-injury in the validation cohort.

(K) Performance, top, and ROC curve, bottom, of the best CSF prognostic model of motor complete vs. incomplete injury at six months at $24 \mathrm{~h}$ post-injury. 
bioRxiv preprint doi: https://doi.org/10.1101/2021.01.27.428528; this version posted January 28, 2021. The copyright holder for this preprint (which was not certified by peer review) is the author/funder, who has granted bioRxiv a license to display the preprint in perpetuity. It is made available under aCC-BY-NC-ND 4.0 International license.

A

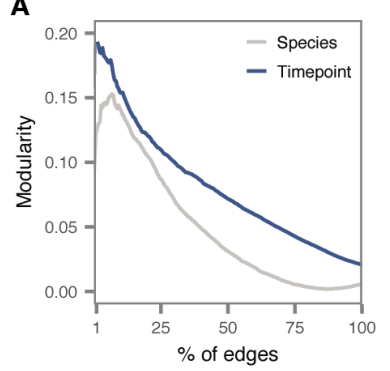

B

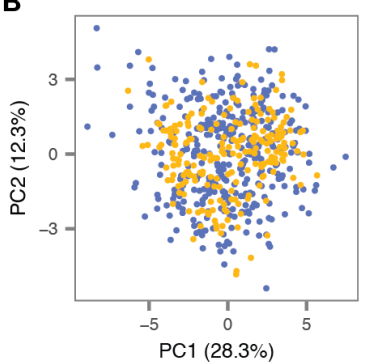

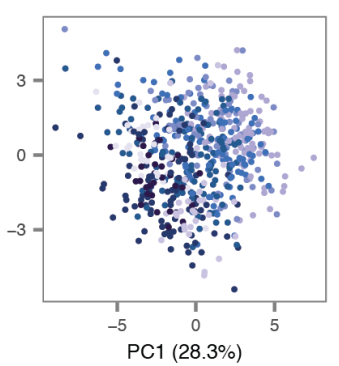

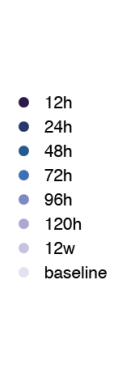

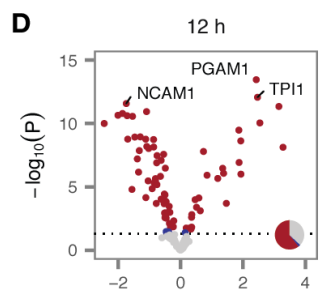
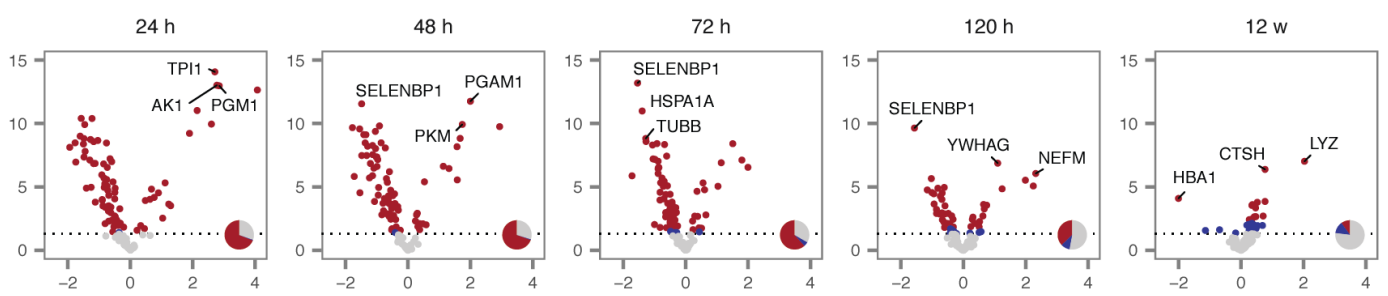

E
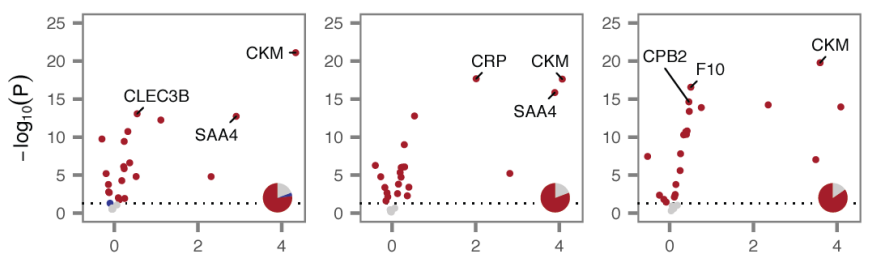

$\log _{2}(\mathrm{FC})$

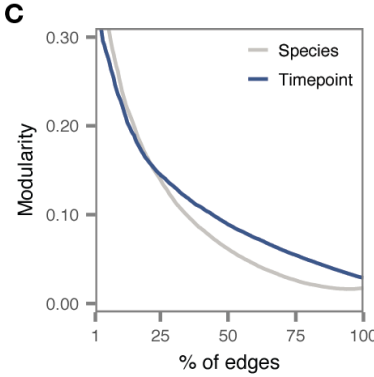

$\mathbf{F}$

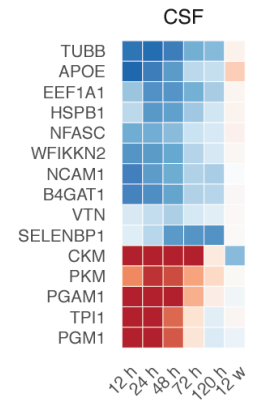

Serum

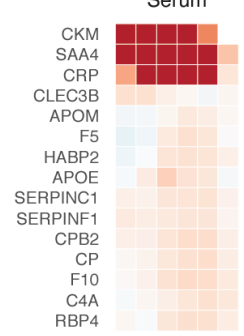

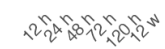

H

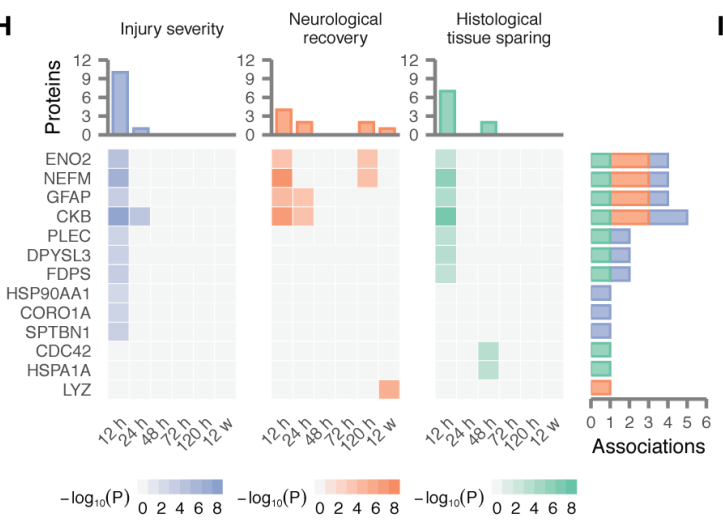

$\mathbf{L}$

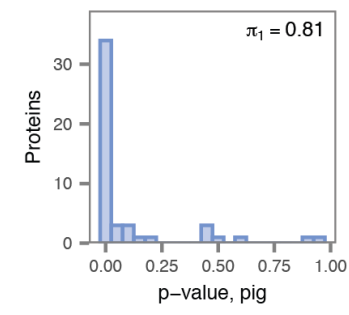

$\mathbf{M}$

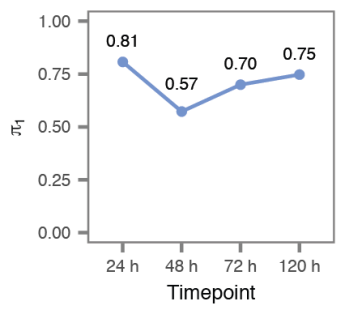

G
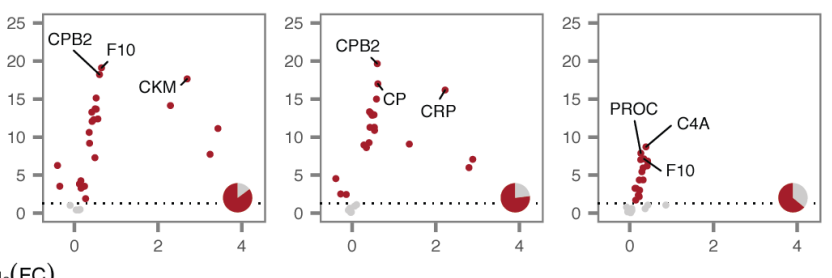

$\log _{2}(\mathrm{FC})$
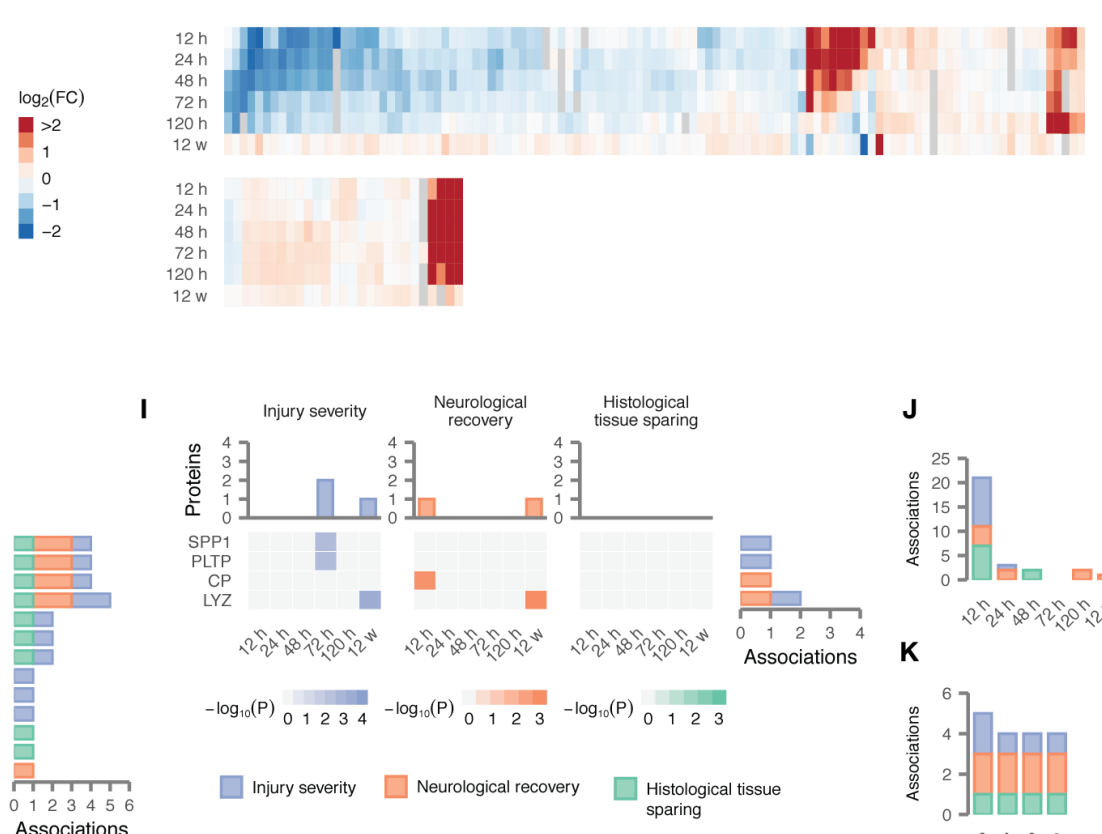

J
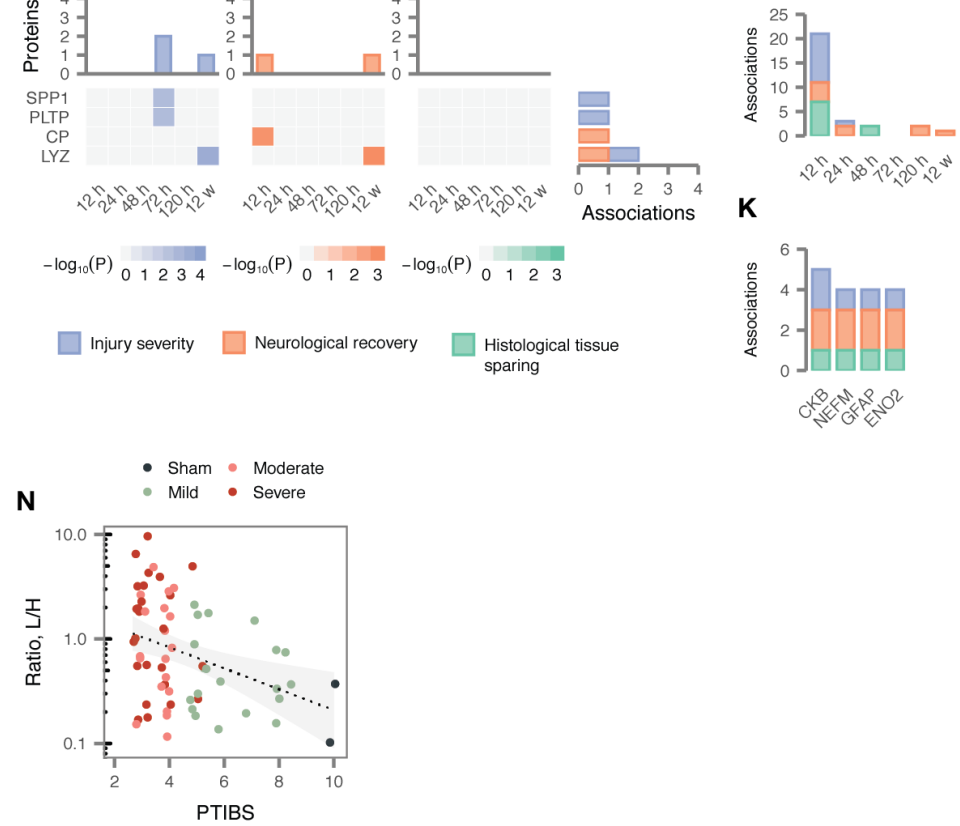
bioRxiv preprint doi: https://doi.org/10.1101/2021.01.27.428528; this version posted January 28, 2021. The copyright holder for this preprint

(which was not certified by peer review) is the author/funder, who has granted bioRxiv a license to display the preprint in perpetuity. It is made available under aCC-BY-NC-ND 4.0 International license.

Fig. S8: Univariate analysis of acute $\mathrm{SCl}$, injury severity, and neurological recovery in pig serum and CSF.

(A) Modularity analysis of the combined human and pig CSF proteomes, with samples grouped by species or time post-injury. Modularity is shown as a function of the number of edges between samples used to construct the network, as a percentage of the total number of possible edges.

(B) Principal component analysis of human and pig serum proteomes, with samples colored by species, left, or time post-injury, right. (C) As in (A), but for the combined serum proteomes.

(D) Volcano plots of differential protein abundance between $24 \mathrm{~h}$ and $120 \mathrm{~h}$ post-injury in CSF samples from injured pigs, compared to samples drawn from the same pigs at baseline (15 min prior to injury).

(E) As in (D), but for serum protein abundance.

(F) Time courses of differential protein abundance $\left(\log _{2}\right.$-fold change, relative to baseline) over twelve weeks post-injury for fifteen of the most profoundly altered CSF proteins, left, and serum proteins, right.

(G) Time courses of differential protein abundance ( $\log _{2}$-fold change, relative to uninjured controls) over twelve weeks post-injury for 135 CSF proteins, top, and 26 serum proteins, bottom, differentially expressed between $\mathrm{SCl}$ and control samples within at least one timepoint.

(H) Statistical significance of associations between CSF protein abundance and three experimental variables over twelve weeks postinjury for 13 proteins with at least one significant association. Grey squares indicate associations that were not significant after correction for multiple hypothesis testing.

(I) As in $(\mathrm{H})$, but for four serum proteins with at least one significant association.

(J-K) Number of statistically significant associations between CSF protein abundance and three experimental variables outcomes per timepoint $(\mathrm{J})$, and for the four CSF proteins with the most recurrent associations $(\mathrm{K})$.

(L) Distribution of p-values for proteins differentially expressed in the CSF of acute SCI patients vs. uninjured controls, in comparisons of pig CSF samples drawn at $24 \mathrm{~h}$ post-injury and at baseline.

(M) Estimated proportion of true associations, $\pi_{1}$, for all human-pig comparisons between $24 \mathrm{~h}$ and $120 \mathrm{~h}$.

(N) Abundance of GFAP in pig CSF samples at $24 \mathrm{~h}$, stratified by PTIBS score. 
bioRxiv preprint doi: https://doi.org/10.1101/2021.01.27.428528; this version posted January 28, 2021. The copyright holder for this preprint (which was not certified by peer review) is the author/funder, who has granted bioRxiv a license to display the preprint in perpetuity. It is made available under aCC-BY-NC-ND 4.0 International license.

A

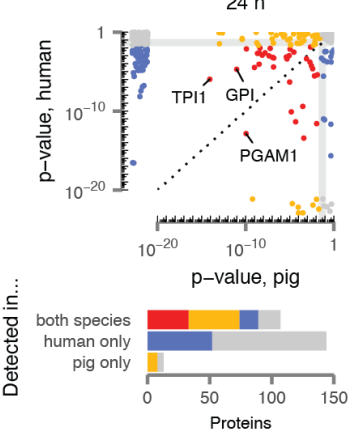

B

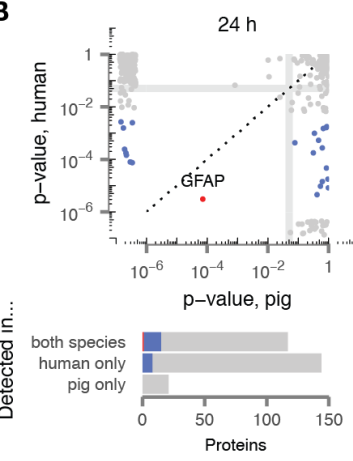

C
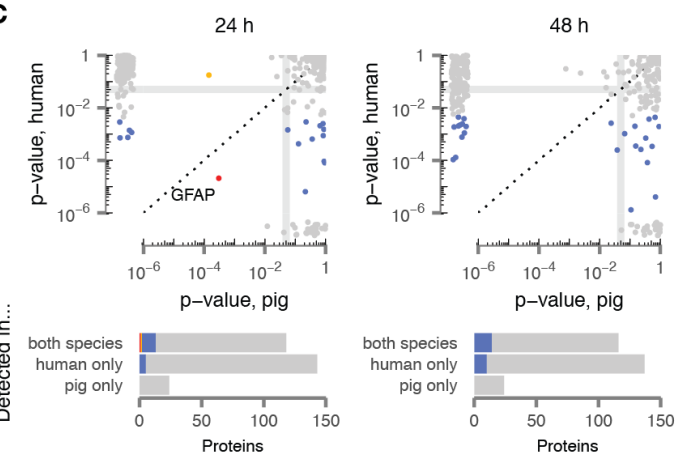

$48 \mathrm{~h}$

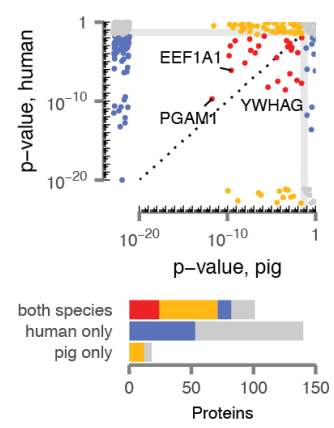

$48 \mathrm{~h}$

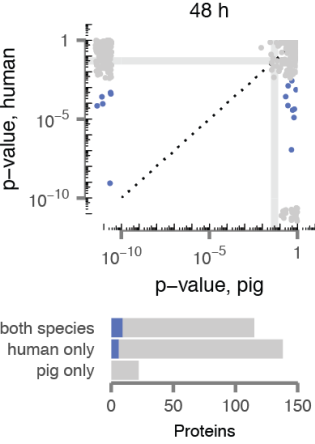

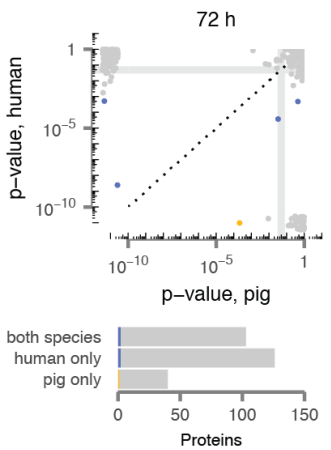

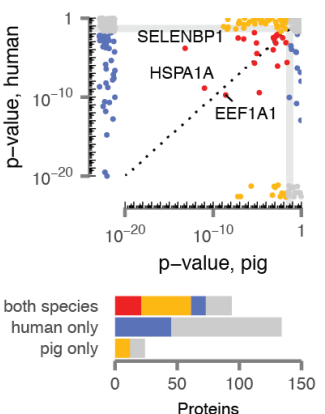

$72 \mathrm{~h}$
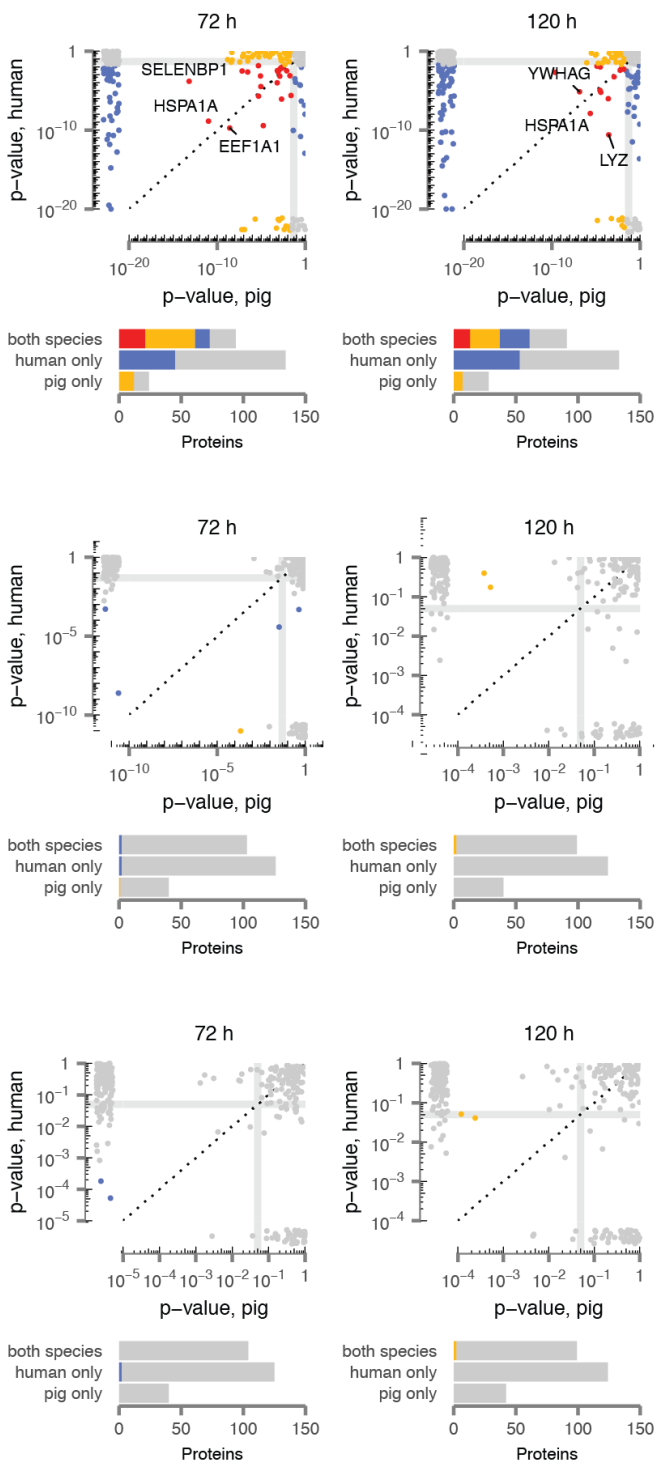

significant? $\square$ n.s. $\square$ human only $\square$ pig only $\square$ both species
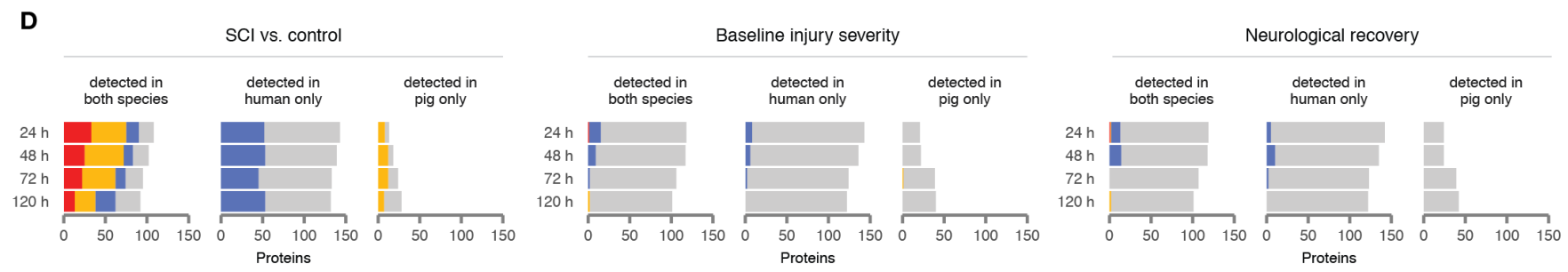

\section{E}
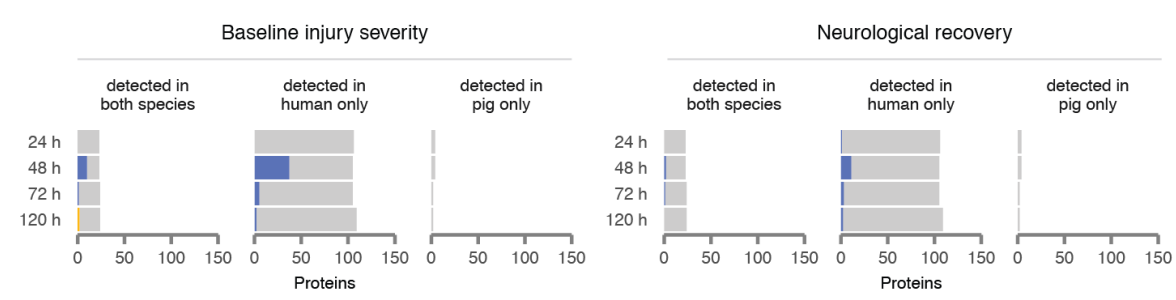
bioRxiv preprint doi: https://doi.org/10.1101/2021.01.27.428528; this version posted January 28, 2021. The copyright holder for this preprint (which was not certified by peer review) is the author/funder, who has granted bioRxiv a license to display the preprint in perpetuity. It is made available under aCC-BY-NC-ND 4.0 International license.

\section{Fig. S9: Overlap of differentially abundant proteins between human and pig.}

(A) Top, p-values for differential protein abundance between samples from individuals with acute SCl and uninjured controls at four matching timepoints in human and pig. Marginal plots show p-values for proteins quantified in human (pig) only. Bottom, number of proteins with statistically significant differential abundance in both species, human only, pig only, or neither, among proteins quantified in both species, human only, or pig only.

(B) As in (A), but for proteins associated with injury severity.

(C) As in (A), but for proteins associated with neurological recovery.

(D) Summary of significant univariate associations involving CSF proteins across species, stratified by (i) clinical or experimental outcome, (ii) time post-injury, (iii) detection in one or both species, and (iv) statistical significance in neither, one, or both species.

(E) As in (D), but for the serum proteome. 
bioRxiv preprint doi: https://doi.org/10.1101/2021.01.27.428528; this version posted January 28, 2021. The copyright holder for this preprint (which was not certified by peer review) is the author/funder, who has granted bioRxiv a license to display the preprint in perpetuity. It is made available under aCC-BY-NC-ND 4.0 International license.

A
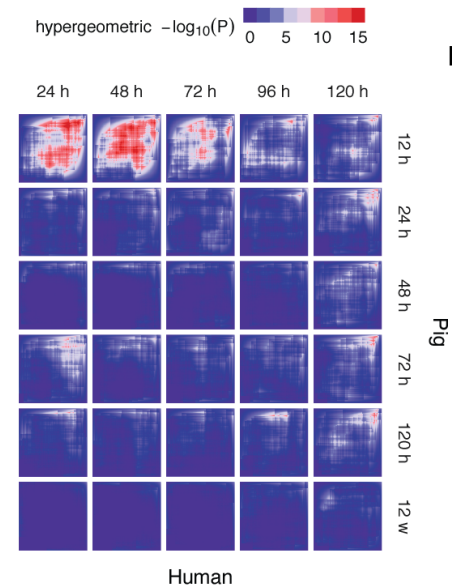

B

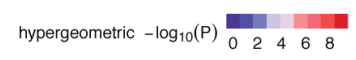

hypergeometric $-\log _{10}(\mathrm{P}) \quad 02468$

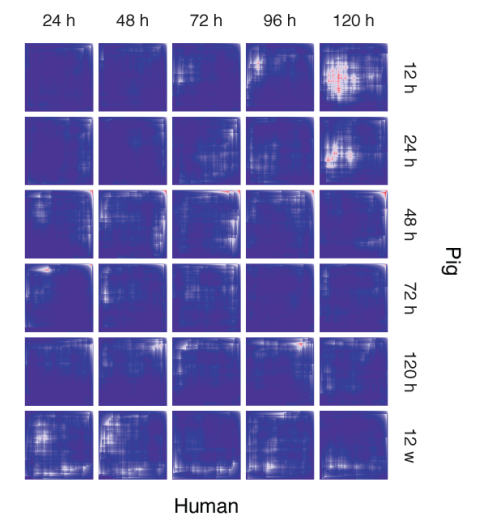

C

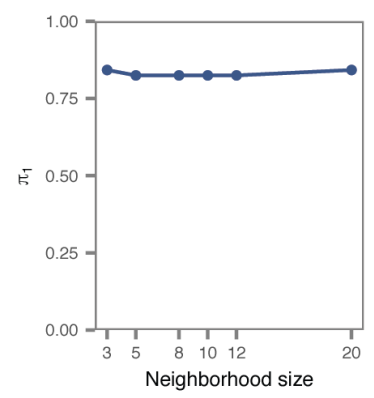

D

- CKB

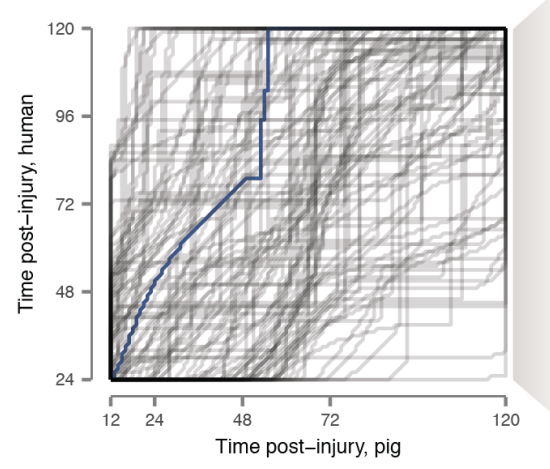

E

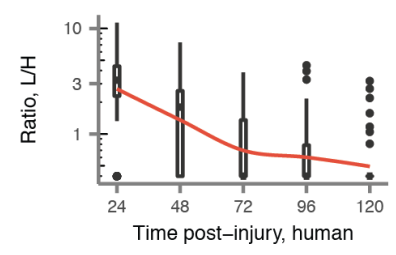

Pig

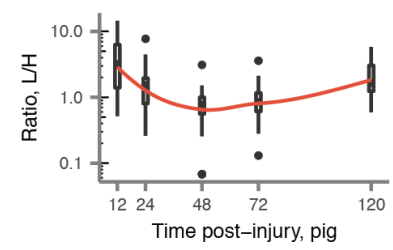

Fig. S10: Cross-species conservation of the proteomic response to SCI.

(A) Rank-rank hypergeometric overlap of proteins associated with injury severity at all pairs of timepoints post-injury.

(B) Rank-rank hypergeometric overlap of proteins associated with neurological recovery at all pairs of timepoints post-injury.

(C) Proportion of true associations, $\pi_{1}$, estimated from neighborhood analysis of conserved coexpression $p$-value distributions with the neighborhood size varied between 3 and 20 neighbors.

(D) Optimal alignments of individual proteins between the human and pig CSF proteomes over the first five days post-injury by dynamic time warping. CKB is shown in blue.

(E) Abundance of CKB in human and pig CSF over the first five days post-injury. Red lines show local polynomial (loess) regression. 